Review Article

\title{
High-Field Growth of Semiconducting Anodic Oxide Films on Metal Surfaces for Photocatalytic Application
}

\author{
Ronald Vargas $\left(\mathbb{D},{ }^{1}\right.$ David Carvajal, ${ }^{1}$ Brunella Galavis, ${ }^{2}$ Alberto Maimone, ${ }^{2,3}$ \\ Lorean Madriz $\mathbb{D}^{1}{ }^{1}$ and Benjamín R. Scharifker $\mathbb{D}^{1,4}$ \\ ${ }^{1}$ Departamento de Química, Universidad Simón Bolívar, Apartado 89000, Caracas 1080A, Venezuela \\ ${ }^{2}$ Departamento de Ciencia de los Materiales, Universidad Simón Bolívar, Apartado 89000, Caracas 1080A, Venezuela \\ ${ }^{3}$ Centro de Tecnología de Materiales, Fundación Instituto de Ingeniería, Apartado 40200, Caracas 1040-A, Venezuela \\ ${ }^{4}$ Rectorado, Universidad Metropolitana, Apartado 76819, Caracas 1070A, Venezuela
}

Correspondence should be addressed to Ronald Vargas; ronaldvargas@usb.ve and Lorean Madriz; lmadriz@usb.ve

Received 12 September 2018; Revised 21 November 2018; Accepted 2 December 2018; Published 25 February 2019

Academic Editor: Adel A. Ismail

Copyright ( 2019 Ronald Vargas et al. This is an open access article distributed under the Creative Commons Attribution License, which permits unrestricted use, distribution, and reproduction in any medium, provided the original work is properly cited.

This work summarizes progresses achieved in the physical chemistry aspects of the growth of anodic oxides under high-field conditions for the synthesis of semiconducting thin solid films and their implementation as photocatalytic materials. We discuss the scope and mechanisms for anodic oxide growth, describing the development of kinetic models and the correlations between theory and kinetic data, leading to fundamental information to characterize the primary processes occurring during the anodization of valve metals under high fields. The main features related to the widely used self-assembly of nanostructures by valve metal anodization are highlighted and briefly discussed. This is followed by general considerations of heterogeneous photocatalysis on these functional materials, considering the kinetics of the heterogeneous catalytic processes involved and the overall photoelectrochemical performance. High control of the characteristics of the materials obtained with the method described, combined with the possibility of electrochemically assisting photocatalysis, allows application of this technology to the treatment of wastewaters, energy conversion, and related fields.

\section{Introduction}

Numerous investigations in recent years have focused on the development of heterogeneous photocatalysts activated by sunlight and their applications to the environmental purification of wastewater, conversion of solar energy, and production of $\mathrm{H}_{2}$ [1-22]. Electrochemically assisted photocatalysis shows superior performance in terms of purification of water from organic matter [12], polarization between two electrodes during the photocatalytic process assisting in separating the charge carriers and catalyzing the redox reactions, thus enhancing the efficiency of mineralization of the pollutants $[12,15,16,23]$. Moreover, efforts have been directed to developing nanostructured photocatalysts of different nature [24-27]. Most applications involve colloidal semiconductors $[8,24,28]$, but the use of large area nanostructured thin solid films has been rapidly growing in the past few years $[12,16]$, and methods to obtain films made of stable materials and/or composites under controlled conditions, with the possibility of modulating the morphology of the nanostructured films, are needed. High-field anodic growth of metal oxide and its alloys offers these possibilities, but to achieve these goals, fundamental understanding of the dynamics of the electrochemical processes in the solid state during metal anodization must be obtained, leading to the rational design of suitable synthetic methods for functional nanostructured films of interest. On the other hand, application of these materials to photocatalytic systems needs the estimation of the kinetic parameters of the heterogeneous reactions 
and the kinetics of the photochemical processes. Furthermore, optimization of the solar to chemical energy conversion during the photocatalytic process requires the design of efficient photochemical reactors, with appropriate comparison of their performance in relation to different photocatalytic systems.

The aim of this work is to summarize the salient physicochemical concepts involved in the growth of anodic oxide films on metal surfaces under high fields, to rationalize the precise control of the structural and morphological characteristics of the semiconductor materials obtained, that this synthetic method allows. We also discuss the heterogeneous photocatalysis based on these functional materials, considering their photoelectrochemical performance as well as the kinetics of the heterogeneous catalytic processes involved, in relation to their use in the environmental problem of treating wastewaters.

\section{Anodic Oxide Growth on Metal Surfaces}

The passivation of iron-based materials was described in 1836 by Schönbein and Faraday, who identified the phenomenon as a chemical process involving the formation of an oxide thin layer on the metal surface [29].

In this case, it is usually observed that metals become passive by formation of dense oxide thin films exhibiting low ionic conductivity, thus inhibiting the active dissolution, $\mathrm{M} \rightarrow \mathrm{M}^{\mathrm{z}+}+\mathrm{ze}^{-}$, or corrosion of the underlying metal, with the oxides representing barriers to the flow of ions and electrons [30, 31]. This leads to valve-like behavior, with current rectification upon reversal of the electrical potential and film thickness proportional to the electric field. The passive thin film is then formed by the anodic reaction depicted by $[30,31]$.

$$
M+\left(\frac{z}{2}\right) \mathrm{H}_{2} \mathrm{O} \rightarrow M O_{z / 2}+z H^{+}+z e^{-}
$$

The anodization reaction (1) leads to the synthesis of highly reproducible thin solid films of valve metal oxides. The anodization process may also occur from lower oxides

$$
M O_{y / 2}+\left(\frac{z-y}{2}\right) \mathrm{H}_{2} \mathrm{O} \rightarrow M O_{z / 2}+(z-y) H^{+}+(z-y) e^{-}
$$

and an oxide film may also be formed by electrocrystallization of ions from solution

$$
M^{y+}+z \mathrm{H}_{2} \mathrm{O} \rightarrow M O_{z / 2}+z H^{+}+(z-y) e^{-}
$$

Anodic potentials enhance passivation according to equations (1)-(3) but transpassivity and anodic breakdown cause the opposite effect [31]. The opposite process implies reduction reactions that destabilize the passive films leading to cathodic breakdown.

Figure 1 shows a simple scheme of the several ionand electron-transfer reactions (ITRs and ETRs, respectively) that may occur during anodization processes; these chemical process may stabilize or dissolve the passive film [30, 31].

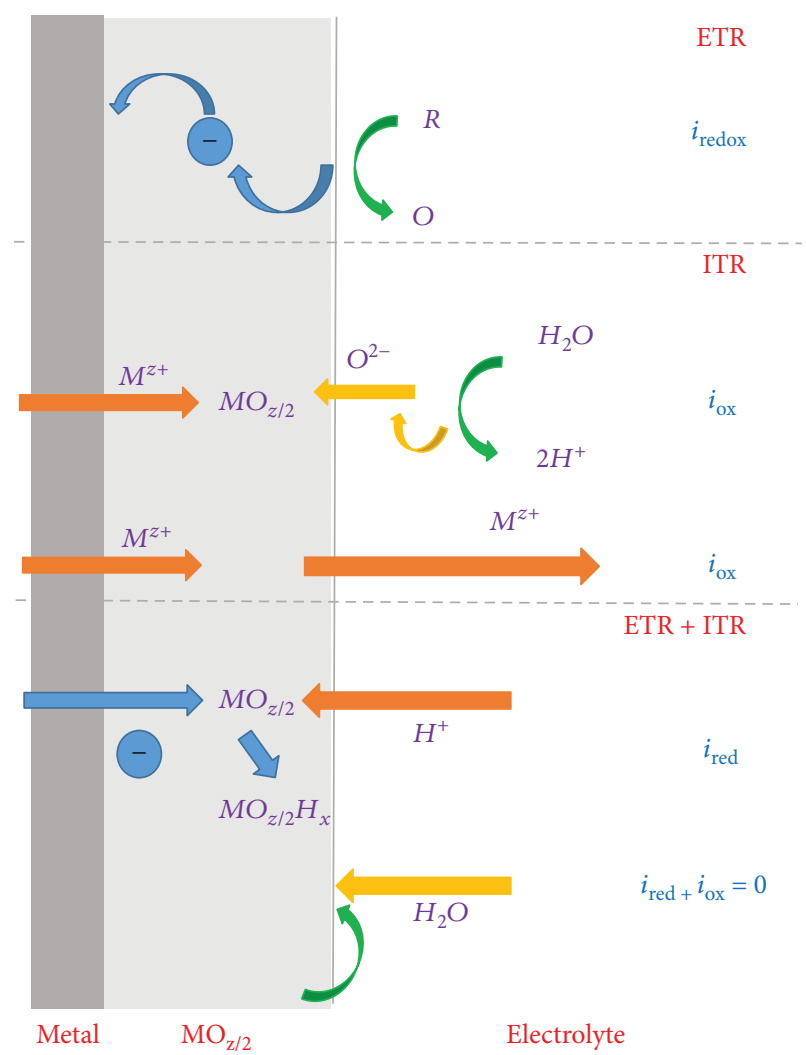

FIGURE 1: Scheme of the several ion-transfer reactions (ITRs) and electron-transfer reactions (ETRs) during the anodization processes.

The most important processes are summarized as follows $[30,31]$ :

(1) Electron-transfer reactions $\left(i_{\text {redox }}\right)$, e.g., oxygen evolution

(2) Growth of the thin oxide film $\left(i_{\text {ox }}\right)$ by the transfer of oxygen ions from the electrolyte into the oxide

(3) Transfer of metal ions from the oxide to solution and oxidation of water $\left(i_{\text {ox }}\right)$

(4) Reduction by the reverse reactions $\left(i_{\text {red }}\right)$

(5) Corrosion, with charge transfer by metal ions compensated by that of oxygen ions $\left(i_{\text {ox }}+i_{\text {red }}=0\right)$

(6) Capacitive charging of the interface $\left(i_{\mathrm{C}}\right)$ upon potential changes

The total current flowing through the interface is then described by

$$
i=i_{\text {redox }}+i_{\text {ox }}+i_{\text {red }}+i_{\mathrm{C}}
$$

Following Young [32], a classification based on the experimental observations indicates that the chemical elements with a complete valve effect are $\mathrm{Al}, \mathrm{Bi}, \mathrm{Sb}, \mathrm{Ta}, \mathrm{Ti}$, and $\mathrm{Nb}$ and those with an incomplete valve effect are Ag, $\mathrm{Cd}, \mathrm{Fe}, \mathrm{Mg}, \mathrm{Si}, \mathrm{Sn}, \mathrm{W}, \mathrm{Zn}$, and $\mathrm{Zr}$, the behavior depending 


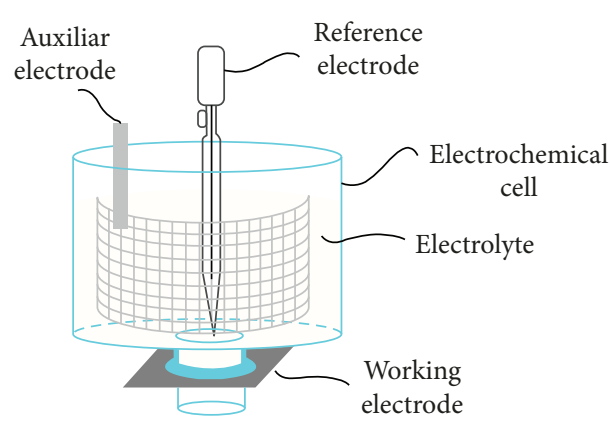

Figure 2: Scheme of experimental setup for obtained thin solid films by the anodization.

on the composition of the solution used during the anodization process [32].

Figure 2 shows a typical experimental setup to obtain thin solid films by the anodization process. The preparation of passive films is affected by the experimental conditions $[30,31]$. The following aspects are usually important: (i) effects due to the presence of a native passive film and pretreatment of the metal surface; (ii) potential-time program for anodization; (iii) chemistry of the solution: $\mathrm{pH}$, possibility of corrosion, nature of supporting electrolyte, presence of ions as possible doping agents, and additives for the promotion of nanostructures; (iv) hydrodynamics (bubble control in the presence of parallel gas evolution reactions, possibility of erosion of the formed passive film, and enhanced mass transport of ions in the case of synthesis of doped thin films); and (v) posttreatment of the metal oxide film as drying, modification, or thermal treatment.

\section{High-Field Anodization}

Oxide films of valve metals can be formed after anodic polarization under high fields higher than $1 \times 10^{6} \mathrm{~V} / \mathrm{cm}$. Under such conditions, oxide growth occurs by ion hopping between regular sites or interstitial positions in the lattice. The hopping mechanism requires an activation energy $W$ which increases exponentially with the jump distance $a$; thus, it is only possible between neighboring sites [30], and the process is catalyzed by imposing increasingly positive potentials.

In general, application of an appropriate anodic polarization implies the formation of an oxide layer involving oxidation of the metal at the metal-oxide interface by reaction with the flux of oxygen ions migrating from the solution across the oxide film, assisted by the electric field. The final result is metal consumption, with the oxide layer growing in the solid state. A representation of this process is shown in Figure 3.

The electrochemical potential of ions and the energies of electrons in the electron bands depend on the local Galvani potential, which is a function of the electronic and ionic conductivities of the metal oxide, the thickness of the film, and the $\mathrm{pH}$ of the solution $[30,31]$. The excess charges at the interface generate a space charge region within the oxide; therefore, local potential changes result in a linear field that controls the migration of charge carriers, i.e., ions and electrons. Metal oxides usually show semiconducting behavior, thus implying capacitive charge accumulation in the solid

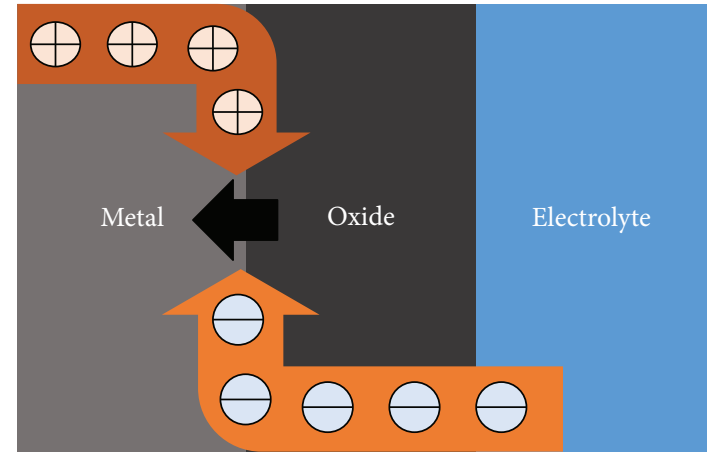

FIGURE 3: Scheme of ion transport during high-field anodization.

state. A potential drop occurs across the film but charge accumulation at the solid-electrolyte interface is only possible for very thin oxide films, in which case the capacitance of the oxide film becomes comparable to the inner Helmholtz plane capacitance at the interface [31]. If the potential drop occurs within the film, then migration of charge carriers within the film controls the anodic growth.

Due to several reasons, films may suffer local enhancement of the conductivity during the anodization process. The oxide lattice may not withstand the large ion or electron fluxes arising at very high fields, or else, high reaction rates of corrosion due to the presence of aggressive chemical species (like chloride or fluoride ions) may locally increase the conductivity, leading to breakdown of the passive film. This may be indicated by several effects such as irregular current peaks, visible sparks, potential fluctuations, increasing electrical noise or even audible noise, depending on the oxide bandgap, and the nature and concentration of ions in solution [30-48].

\section{Kinetic Model}

In order to represent the high-field anodization phenomenon, Figure 4 shows two lattice planes corresponding to stable sites at the positions " $x$ " and " $x+a$," then the ion flux $\mathrm{d} n / \mathrm{d} t$ at the metal-oxide interface can be obtained from the reaction rate in terms of the mole balance for the transference [30].

$$
\frac{\mathrm{d} n}{\mathrm{~d} t}=\frac{\mathrm{d} n_{\rightarrow}}{\mathrm{d} t}-\frac{\mathrm{d} n_{\leftarrow}}{\mathrm{d} t}=n_{(x)} p_{\rightarrow}-n_{(x+a)} p_{\leftarrow},
$$

where $n_{\rightarrow}$ and $n_{\leftarrow}$ stand for the ion movements in either direction across the film and $p_{\rightarrow}$ and $p_{\leftarrow}$ are the probabilities of the atomic hopping processes, equivalent to kinetic constants for the microscopic balance. Their values can be estimated with an Arrhenius type relationship.

$$
p=\vartheta \exp \left(-\frac{W}{R T}\right)
$$

where $\vartheta$ is the attempt frequency for the hopping ions and $W$ is the activation energy of this process. In Figure 4, the ions are centered in stable positions in the lattice; these stable positions imply minima in the potential energy of the crystal.

In the absence of an electric field, the activation energy and the hopping probabilities are equal for both hopping 


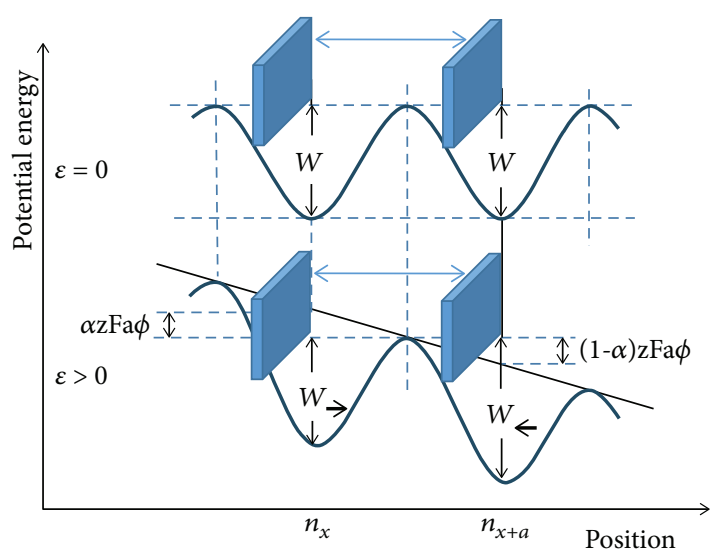

Figure 4: Effect of the electric potential on the activation barrier for the hopping mechanism between two adjacent planes in the oxide lattice.

directions. An electric field contributes to the potential energy and catalyzes the hopping mechanism due to the asymmetry generated in the energy-position coordinate profile (see Figure 4), the potential providing free energy to decrease the effective energy barrier.

Considering the fundamental chemical kinetics theory for electrochemical processes by Butler and Volmer (see details and other considerations in, e.g., $[30,33])$, the activation energy can be rewritten as

$$
W_{\rightarrow}=W-\alpha a z F E_{f}
$$

and

$$
W_{\leftarrow}=W-(1-\alpha) a z F E_{f},
$$

where $\alpha$ is the transfer coefficient that describes the symmetry of the activation barrier, $\alpha$ defines the distance between positions of minimal energy, $z$ is the charge number of the electroactive species, $F$ is the Faraday constant, $E_{f}$ is the field strength, and $E_{f}=\left(E-E^{\circ}\right) / d$, where $E$ is the applied potential, $E^{\circ}$ is the equilibrium potential of the oxide electrode, and $d$ is the thickness of the film.

Then, the reaction rate can be expressed in terms of the current flux at the interface after the consideration of the Faraday second law $(i=z F(d n / d t))$ and substitution of (6), (7), and (8) in (5) yields

$$
i=a \vartheta \rho_{C} \exp \left(-\frac{W}{R T}\right)\left\{\exp \left(\frac{\alpha a z F E_{f}}{R T}\right)-\exp \left[\frac{(1-\alpha) a z F E_{f}}{R T}\right]\right\},
$$

where $\rho_{C}=(n / a) z F$ is the concentration of mobile charges.

Furthermore, the presence of a high electric field implies ion movement in the growth direction; the opposite movement is improbable thus the high-field reaction rate becomes

$$
i=a \vartheta \rho_{C} \exp \left(-\frac{W}{R T}\right)\left[\exp \left(\frac{\alpha a z F E_{f}}{R T}\right)\right] .
$$

After recognizing that the exchange current is $i_{0}=a \vartheta \rho_{C}$ $\exp (-(W / R T))$ and the Tafel slope is $\beta=\alpha a z F / R T$ and substituting $E_{f}=\left(E-E_{0}\right) / d$, (10) simplifies into (11) as follows:

$$
i=i_{0}\left\{\exp \left[\beta \frac{\left(E-E_{0}\right)}{d}\right]\right\}
$$

This is a simple relation that indicates the exponential dependence of the reaction rate with the applied potential. The correspondence of the current-time experimental data obtained at constant potential with (11) thus indicates that the rate-determining step for the oxide growth is the movement of the ions within the oxide. Additionally, if the potential drop occurs only within the film, with $100 \%$ Faradic efficiency for film growth, i.e., no oxide dissolution, no oxygen evolution nor capacitive charging, then the film thickness can be estimated as [34]

$$
d=d_{0}+\frac{M}{z F A \rho_{\text {ox }}} \int_{0}^{t} i(t) d t
$$

where $d_{0}$ is the oxide film thickness initially present, $\rho_{\mathrm{ox}}$ the oxide density, $A$ is the electrode surface area, $M$ the oxide molecular weight, and $\int_{0}^{t} i(t) d t$ is the charge transferred for oxide growth.

This result indicates the possibility of describing the oxide thickness during valve metal oxide growth as a linear function of the charge passed during anodic polarization, and it is an important feature for controlling the synthesis of thin films of metal oxide semiconductors. Another significant feature of this methodology is that the potential determines the kinetics of the phenomena that occur at the interface.

\section{Metal Oxide Nanotubes Synthesized by High-Field Anodization}

In 1999, Zwilling and coworkers reported a simple methodology for the synthesis of self-organized metal oxide nanotubes based on the high-field electrochemical anodization technique in $\mathrm{HF}$ electrolytes [49]. $\mathrm{TiO}_{2}$ nanotubes were the first nanostructures obtained, but the approach was extended to other valve metals as tungsten, zirconium, hafnium, thallium, titanium alloys, and diverse valve metals alloys $[22,27,50]$. In general, highly ordered arrays of vertically aligned nanotubes or nanopores result from this electrochemical synthesis, in a closely packed structure and with a wide range of characteristics for functional applications, such as

(i) high photocatalytic activity

(ii) high resistance to the photocorrosion process

(iii) good biocompatibility for drug release systems

(iv) good electrode materials for diverse sensing applications

(v) electrodes suitable for Li ion batteries and fuel cells 


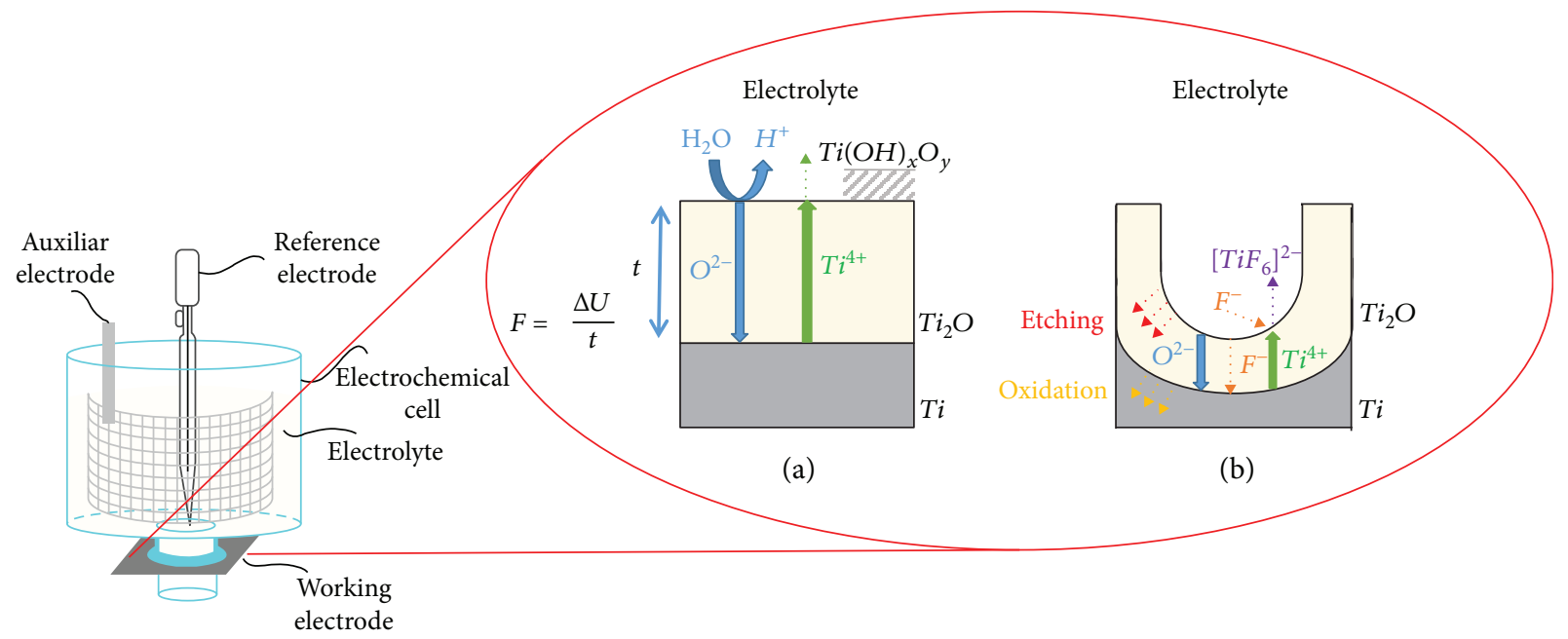

FIGURE 5: Anodization process representation in (a) absence of fluoride electrolyte and (b) presence of fluoride electrolyte.
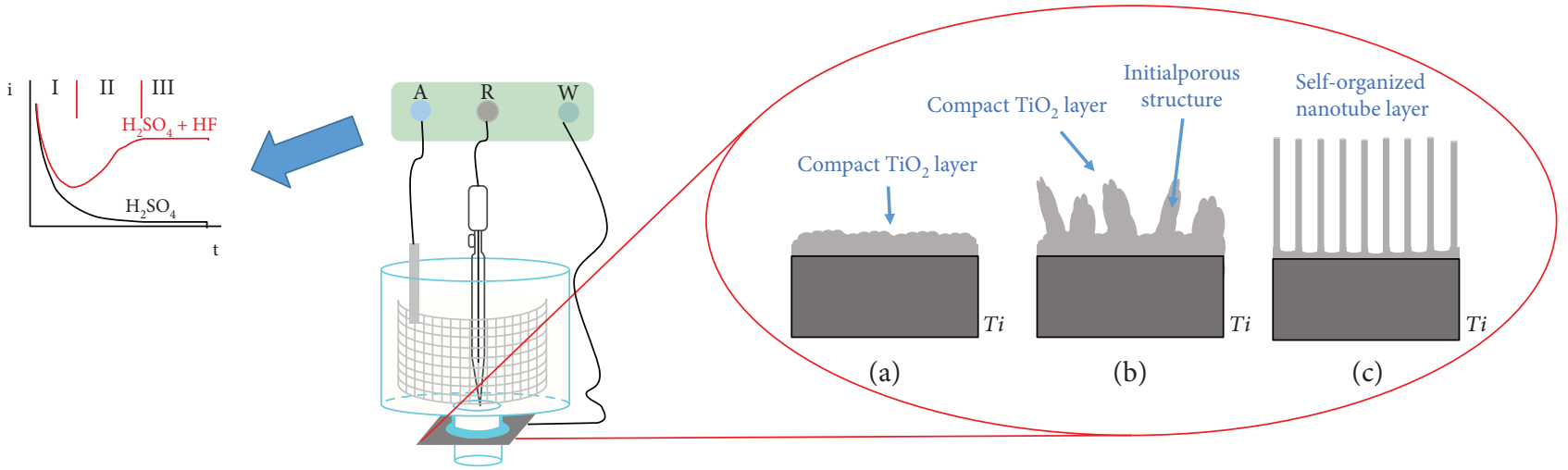

FIGURE 6: Key steps during the self-organized nanotube layer formation based on anodization process in fluoride electrolyte.

(vi) good materials for solar energy conversion in solar cells

(vii) self-cleaning materials

(viii) materials for new optical devices

As discussed below, whether oxidation leads to the anodic growth of a compact oxide on the metal surface or the formation of an array of nanotubes is determined by the competition of two chemical processes: the anodic oxide formation at high fields defined by (1) on the one hand and the chemical dissolution of the oxide through the formation of fluoride complexes

$$
\mathrm{MO}_{z / 2}+(z+2) F^{-}+z H^{+} \rightarrow\left[M F_{(z+2)}\right]^{2-}+\frac{z}{2} \mathrm{H}_{2} \mathrm{O}
$$

on the other. The formation of complexes may occur also by direct reaction of fluoride with the metal cation transported by the high field at the oxide-electrolyte interface:

$$
M^{z+}+(z+2) F^{-} \rightarrow\left[M F_{(z+2)}\right]^{2-}
$$

Figure 5(a) shows a simple scheme to visualize the microscopic transport phenomena that occur during the high-field anodization of titanium in aqueous electrolyte. In the presence of fluoride ions, Figure 5(b), the situation changes dramatically by dissolution of $\mathrm{TiO}_{2}$ at the electrode-electrolyte interface. At least two new phenomena need to be considered, (i) the ability to form water-soluble $\mathrm{TiF}_{6}{ }^{2-}$ complexes and (ii) the incorporation of fluoride into the growing film due to its small ionic radius, implying the field-assisted transport of this ion through the oxide film and thus competing with the transport of oxygen ions $\mathrm{O}^{2-}$ in the solid state. The initial nanopores formed at the surface develop in a nanotubular array due to the competition of the high-field electrochemical formation of $\mathrm{TiO}_{2}$ and the formation of Ti-F complexes by the chemical attack of fluoride to the formed $\mathrm{TiO}_{2}[22,50]$.

Figure 6(a) depicts the current-time curve registered from high-field anodization with formation of a nanotube array film. In this case, the electrolyte is an aqueous solution containing fluoride ions. Three stages are observed: in phase I, an initial exponential decay of the current, then the current increases during phase II after a time delay dependent on the fluoride concentration, with shorter delays at higher fluoride concentrations. In phase III, the 


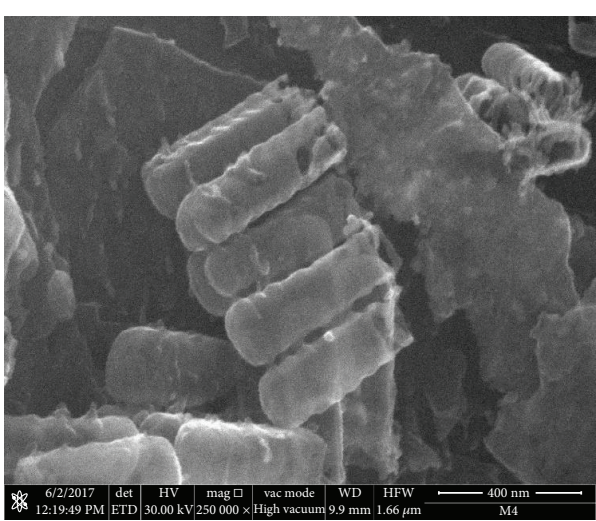

(a)

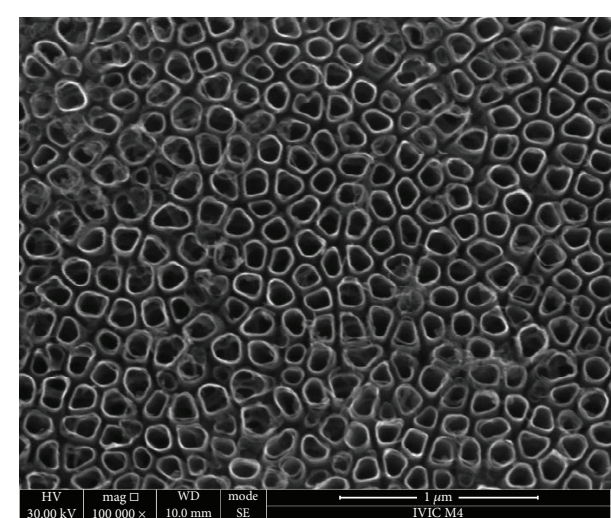

(b)

FIgURE 7: Experimental $\mathrm{TiO}_{2}$ nanotubes obtained after the anodization of Ti foil synthetized according to the methodology reported in [52].

current reaches a steady state at a value directly proportional to the fluoride concentration in solution. Figure 6(b) depicts the steps involved in the formation of the nanotube array film. A barrier oxide is formed during phase I leading to the decay of the current; during phase II, the surface is locally activated with pores which start to grow randomly, increasing the active area and originating the rising current. In phase III, the pores interfere with each other as the chemical process of film formation and dissolution far from equilibrium is maintained, leading to a steady-state dissipative structure with minimal entropy production [51]; in this stage, the current flow is equally shared by the available pores, and self-ordering conditions are established. A rigorous treatment of self-ordering in the formation of nanotubes is still lacking; theoretical and experimental studies are needed to elucidate it and contribute to the rational optimization of the synthesis of nanotubes. Notwithstanding, the evidence available makes it clear that according to the scheme presented in Figure 6, self-ordered nanotubular films of valve metals can be formed by high-field anodization in fluoride-rich electrolytes. Figure 6(c) shows the ideal nanotubular array film, correlating its formation to the competing rates of the two major phenomena, the electrochemical growth of the metal oxide and its chemical dissolution by formation of the metal-fluoride complex [22, 50].

According to the discussion above, the factors to consider for the synthesis of nanostructured films are (i) a high-field anodization protocol with a valve metal or an alloy of these metals, (ii) a potential-time program for anodization, (iii) an electrolyte containing fluorides, and (iv) the effects of a native passive film and pretreatment of the metal surface. Currently, self-assembled nanotube films of several semiconductors such as $\mathrm{TiO}_{2}, \mathrm{WO}_{3}, \mathrm{ZrO}_{2}, \mathrm{HfO}_{2}, \mathrm{Ta}_{2} \mathrm{O}_{5}, \mathrm{Nb}_{2} \mathrm{O}_{5}$, doped materials, binary alloys such as TiAl, TiNb, TiW, and $\mathrm{TiZr}$, and biomedical alloys such as $\mathrm{Ti}_{6} \mathrm{~A}_{17} \mathrm{Nb}$ and $\mathrm{Ti}_{29} \mathrm{Nb}_{13} \mathrm{Ta}_{4.6} \mathrm{Zr}$ have been reported $[22,50]$.

According to the literature [22], nanotube arrays with the following characteristics have been synthesized:

(1) Directly attached to the metal

(2) Annealed to an appropriate crystal phase
(3) Typical dimensions ( $\mathrm{TiO}_{2}$ nanotubes):

(a) Length: $100 \mathrm{~nm}$ to $100 \mu \mathrm{m}$ (related to the anodization time)

(b) Diameter: $10 \mathrm{~nm}$ to $500 \mathrm{~nm}$ (related to the voltage)

(c) Wall thickness: 2 to $80 \mathrm{~nm}$

The shape of the nanostructures can be controlled with the anodization voltage and the fluoride content or the nature of the fluoride chemical compound used in the electrolyte. Figure 7 shows examples of shapes obtained in the case of $\mathrm{TiO}_{2}$ nanotubes.

\section{Photocatalysis Based on Metal Oxides Synthesized under High Fields}

6.1. General Considerations. The metal oxides synthesized by anodization methods typically result in a thin film with the semiconductor material attached to the metal substrate. This may represent an advantage for the collection of electrons generated during the light activation resulting in good efficiencies. Additionally, these films present good mechanical properties, such as high resistance to erosion and corrosion.

The crystallinity of the semiconductor films may be improved after synthesis subjecting them to thermal treatments to promote phase transitions. The crystal phase determines the possibility of using the semiconductor material in some applications, the transformation depending on the temperature and pressure employed in a muffle reactor, and the use of an inert or an oxygen-rich atmosphere promoting stoichiometric or nonstoichiometric growth of the new phases. In certain occasions, mixed phases are of interest and in order to synthesize these materials, an initial phase is at first formed, with new conditions imposed later in accordance to the phase diagram of the material, with the kinetics of the phase transition determining the rate of synthesis of the new material.

Doping the thin films formed by anodization is possible, either by incorporation of foreign ionic chemical species in a second anodization bath, by surface modification during a thermal treatment with a vapor compound, or by equilibrium 


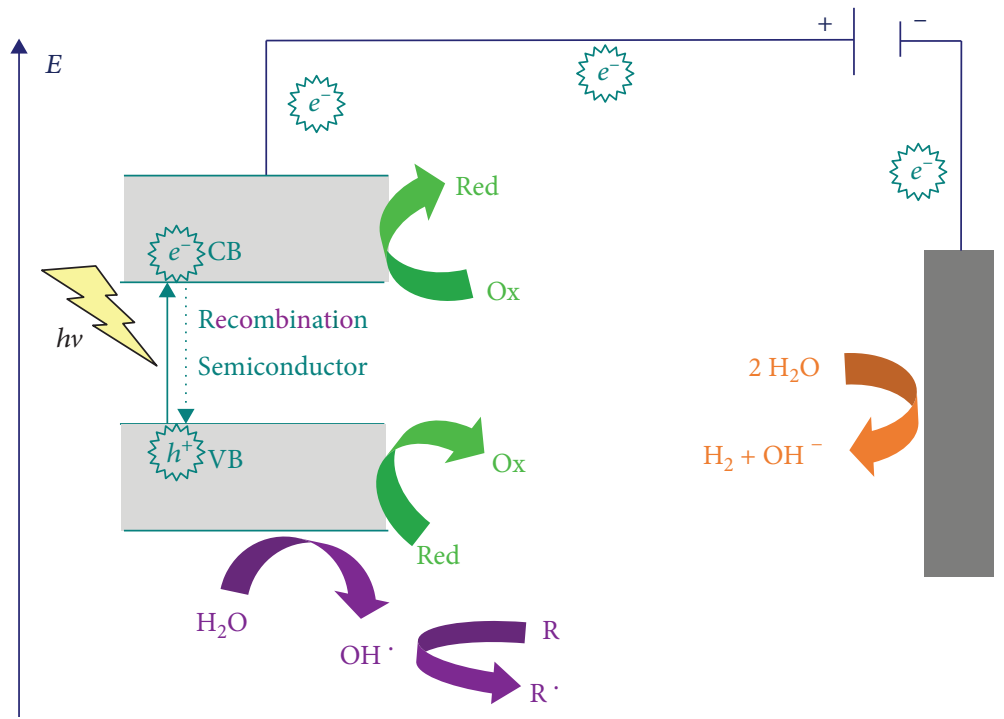

FIGURE 8: Scheme of electrochemical assisted photocatalysis.

adsorption of organic or inorganic compounds from aqueous solution [16].

In general, characterization of the anodic thin films is needed, and diverse experimental techniques have been developed for these purposes: optical, electronic and/or atomic microscopy [50], electrochemical measures controlling voltage, current densities or charges [30-48], electrochemical impedance spectroscopy [53, 54], gravimetric measurements with the electrochemical quartz microbalance $[55,56]$, infrared absorption, Raman, laser, UV-vis, UV-vis reflectance, luminescence, acoustic, $\mathrm{X}$-rays, resonance, ellipsometry, and neutron-based spectroscopies [15, 44-47, $50,57-62]$, and dynamic characterization based on photoelectrochemical methods $[23,63,64]$.

6.2. Photocatalytic Considerations. Under conditions of $\mathrm{MOx} /$ solar light photocatalysis, an electron from the valence band is promoted to the conduction band [65]:

$$
\mathrm{MO}_{x}[]+h v \rightarrow \mathrm{MO}_{x}\left[e^{-}+h^{+}\right]
$$

generating a hole $h^{+}$in the valence band (VB) and an electron $e^{-}$in the conduction band (CB). The holes can react with organic compounds to generate free radicals.

$$
h^{+}+\mathrm{R} \rightarrow \mathrm{R}^{\bullet+}+e^{-}
$$

They can also be trapped by water to form hydroxyl radicals on the surface of the photocatalyst:

$$
h^{+}+\mathrm{H}_{2} \mathrm{O} \rightarrow \mathrm{HO}^{\bullet}+\mathrm{H}^{+}+e^{-}
$$

Charge balance is preserved by reaction of electrons in the $\mathrm{CB}$ with acceptor species dissolved in the aqueous solution. Thermodynamically, the reduction potential of this chemical species must be equal or more positive than the potential corresponding to the edge of the $\mathrm{CB}$ of the semiconductor; another necessary condition for reactivity is that the electron density of the redox couple in the electrolyte must overlap with the density of states of the CB. Frequently, overall charge balance is completed by the oxygen reduction reaction under solar light irradiation

$$
e^{-}+\mathrm{O}_{2} \rightarrow \mathrm{O}_{2}^{\bullet-}
$$

or by reduction of an oxidized species $O x$ in solution capable of being reduced by an electron from the conduction band

$$
e^{-}+\mathrm{Ox} \rightarrow \operatorname{Red}
$$

Additionally, reduction can be electrochemically assisted, this implies separating the anodic and cathodic reactions, and after polarization, the electron at the $\mathrm{CB}$ can be extracted to the external circuit, enhancing charge separation, as shown in Figure 8. Consequently, electron-hole recombination diminishes and general improvement of the light-induced redox reactions obtain.

6.3. Reaction Kinetics of the Photocatalytic Process. There are several parameters that influence the photocatalytic process $[65,66]$, for instance, the intensity of the radiation that reaches the surface of the photocatalyst. This variable is particularly important when the process is carried out on a pilot scale with an irradiance affected by the weather. When a photocatalytic reaction is carried out in a pilot-plant reactor, the reaction time needs normalization with respect to the intensity of incident radiation; otherwise, when considering time as an independent variable, its variation throughout the process by cloud cover and the distribution of the radiant flux in the reactor should be taken into account [67]. This problem has been addressed introducing a standardized lighting time $t_{I p W}{ }_{n}$ accounting for the average radiation intensity

$$
t_{I p W, n}=t_{I p W, n-1}+\Delta t_{n} \frac{I^{\exp }\left(t_{n}\right)}{I p} \frac{V_{\mathrm{i}}}{V_{\mathrm{T}}}, \quad \Delta t_{n}=t_{n}-t_{n-1},
$$


where $I p^{\exp }(t n)$ is the average of solar irradiation intensity measured during an experimental time interval $\Delta t_{n}$ and $V_{\mathrm{i}}$ and $V_{\mathrm{T}}$ represent the irradiate volume in contact with the photocatalyst and the total volume of the reactor, respectively. For photocatalysts that absorb UV light, as $\mathrm{TiO}_{2}$, the typical UV power $I p=30 \mathrm{~mW} / \mathrm{cm}^{2}$ of a perfectly sunny day is usually used. In the case of using photocatalysts that absorb visible radiation, (20) can be used considering the average solar radiation of the spectrum of a sunny day, $I p=1000-1500 \mathrm{~W} / \mathrm{m}^{2}$ or some value that can be determined, or considered representative for the experimental setup. Advanced considerations for the design and operation of photocatalytic reactors have been reviewed [68].

In the case of photocatalysis based on thin solid films obtained by the high-field anodization method, the nature of the film material, the disposition of the film with respect to the illumination, and the possibility of the electrochemical assisted photocatalysis influence the photocatalytic process $[12,15]$. The morphology, crystal phase, and composition of the nanocatalyst affect the performance $[12,69]$. Also, in photocatalytic reactions, the $\mathrm{pH}$ of the solution determines the charge of the catalyst surface. For example, changes in the $\mathrm{pH}$ can result in an improvement of the efficiency in the photocatalytic removal of pollutants in the presence of $\mathrm{TiO}_{2}$, due to the impact of the adsorbed states on the reaction rate on the photocatalyst [70-73].

Another significant factor in the study of the chemical kinetics of photocatalysis is the nature and concentration of the substrate $[28,74]$. Studies of concentration effects at otherwise constant conditions allow estimating the kinetic constants that characterize the reaction. The concentration of the organic substrate influences the saturation of active sites on the catalyst surface, deactivating them at high concentrations [75]. At typical radiation intensities at the surface of the Earth, photocatalytic reactions for the decomposition of organic compounds dissolved in water can be described according to the kinetic model of Langmuir and Hinshelwood. Basically, it involves fast establishment of adsorptiondesorption equilibrium of the organic compound on the surface of the photocatalyst, with subsequent surface reaction of the adsorbed species with photogenerated hydroxyl radicals. The rate law describing such behavior is expressed by

$$
r=\frac{k K c}{1+K c},
$$

where $r$ is the reaction rate, $c$ the concentration of the organic compound, $k$ is the rate constant of the surface reaction between hydroxyl radicals and organic compound, and $K$ is the equilibrium constant of adsorption-desorption of the organic compound on the surface of the photocatalyst $[5,65]$. From this model, it can be seen that the kinetics of the reaction changes from first order to zero order as the concentration of the substrate increases, since with $K c<<1$ the reaction rate becomes proportional to the concentration and with $K c>>1$ the kinetics is independent of the concentration. Thus, the observed reaction constant turns out to be inversely proportional to the concentration of the organic compound, $k_{\mathrm{obs}}=k K /(1+K c)$. This is difficult to detect from $\ln c$ vs. $t$ plots [76]. However, upon plotting the inverse of the initial reaction rate as a function of the inverse of the initial concentration, a linear response is obtained and the kinetic constants characterizing the reaction on the specific photocatalyst can be determined as $k$ $=1 /$ intercept and $K=$ intercept/slope [5, 28, 65, 77]. When considering a multicomponent system or when reaction intermediaries accumulate significantly, the LangmuirHinshelwood model takes the following form:

$$
r=\frac{k K c}{1+K c+\Sigma K_{i} c_{i}},
$$

where $\sum K_{i} c_{i}$ represents the contribution of the $i$-th components of the system; thus, the photocatalytic reaction involves a thermodynamic contribution, the adsorption of the adsorbate on the catalyst surface characterized by $K$, and a kinetic contribution due to the reaction of the adsorbate with the oxidant agents formed by electron transfer to the hole at the VB of the semiconductor, characterized by $k$.

\section{Application of High-Field-Grown Semiconducting Anodic Oxide Films to Photocatalytic Processes}

7.1. Photo(electro)catalysis. Photocatalysts obtained by high-field anodization have been reported [22, 78, 79, 82-86] with growing interest on self-assembled nanostructures, such as nanotubes of $\mathrm{TiO}_{2}$ and other materials $[16,22,26,27,50]$. Additionally, mineralization has been observed with electrochemically assisted photocatalysis $[12,22]$ and photocatalytic oxidations without polarization have been also reported $[9,50]$, but, in general, these reports have not been supported by kinetic studies to determine oxidation parameters, hindering identification of conditions for efficient mineralization. The simplest kinetic model to interpret heterogeneous photocatalysis, as discussed above, is that of Langmuir and Hinshelwood, and some reports explore the degradation of pollutants on semiconductor materials synthesized by anodization in terms of this kinetic model $[9,28,75,79-81]$. Better understanding of the chemical kinetic principles of photocatalytic processes with application of bias potentials is also of interest $[75,82,83]$.

In recent years, efforts have been oriented in the structural modification of nanometric materials obtained by high-field anodization. The nonmetallic doping by thermal treatments in controlled atmosphere is a common strategy to obtain nanotubes of $\mathrm{TiO}_{2}$ with high oxygen vacancy density and $\mathrm{Ti}^{3+}$ in the structure. This results in new energy levels below the conduction band, increasing the density of charge carriers, improving the separation of charges by capture of electrons, and extending absorption towards the visible range $[84,85]$. In addition, nanotube materials have been modified by decoration with metallic nanoparticles or semiconductors improving the generation and separation of charges $[86,87]$. These electrodes are chemically stable and are presented as good candidates for the treatment of wastewater both by their high capacity to generate hydroxyl 
radicals [88] as well as photoanodes in photoelectrochemical cells for the production of $\mathrm{H}_{2}$ through the water-splitting reaction [88-90].

The properties of the photocatalyst may be tuned changing the synthesis conditions. For example, mixed oxide nanotube layers of TiNb, TiMo, and TiW have been tested, and it has been found that under visible light-induced photocatalysis, the TiW oxide tubes show very high efficiency for methyl orange degradation [91-95]. A common approach has been to decorate the film with nanoparticles of $\mathrm{Ag}, \mathrm{Au}$, and alloys, other oxide materials, or by adsorption of dye sensitizers, with application of external bias. With these, increased photocatalytic activities have been invariably researched $[78,96,97]$. The many reports on the degradation of aliphatic alcohols [98-100], aliphatic carboxyl acids [98-101], aromatic alcohols [99, 102, 103], aromatic carboxyl acids [99, 100, 104], chloroaromatic compounds $[99,105]$, aromatic nitro compounds [106, 107], amino acids and derivates [99, 108], aromatic amines [109], surfactants [110], herbicides [111], and dyes [112-114] indicate that the materials obtained by the high-field anodization method are able to solve, with high efficiency, the environmental problem of wastewaters.

7.2. Analytical Chemistry and Sensing. Taking advantage of the good photocatalytic and structural characteristics of materials synthetized under high-field anodization, various applications as active elements for chemical sensors have been developed.

$\mathrm{TiO}_{2}$ nanostructures have been used as photoelectrodes for the determination of chemical oxygen demand (COD) $[115,116]$. The results demonstrated the possibility to achieve total oxidation of organic matter composed of diverse organic compounds. The COD study covered the range between 0 and $850 \mathrm{mg} \mathrm{O}_{2} / \mathrm{L}$ with good results in the presence of chlorides between 0 and $2000 \mathrm{ppm}$ and $\mathrm{pH}$ between 4 and 10. In addition, the time of the determination was reduced to intervals between 1 and $5 \mathrm{~min}$. As an added value of these investigations, the design, construction, and commercialization of the COD detection equipment were obtained. The technology based on $\mathrm{TiO}_{2}$ nanostructures formed by high-field anodization results in the principal component of the commercial analyzer COD PeCOD ${ }^{\mathrm{TM}}$ from ManTech Inc. The equipment is robust and requires the use of a source of ultraviolet radiation to activate the electrode; the time of average sampling is around $15 \mathrm{~min}$. Recent reports improve reaction conditions for the use of modified $\mathrm{TiO}_{2}$ nanotubes [117].

An additional widely documented application is the detection of $\mathrm{H}_{2}[15,22,118,119]$. The interaction of a gas with a metal oxide semiconductor is primarily a surface phenomenon. Therefore, nanoporous metal oxides offer the advantage of providing large sensing surface areas. It is known that the electrical resistance of materials such as $\mathrm{TiO}_{2}$ nanotubes is sensitive to $\mathrm{H}_{2}$, and the detection process is reversible. In general, the $\mathrm{H}_{2}$ sensor based on nanotubes demonstrated good sensitivity for the wide-range detection of dilute hydrogen atmospheres and high concentrations. For example, typical measurements ranging from $50 \mathrm{ppm}$ to
$2 \% \mathrm{H}_{2}$ were reported. Another interesting feature is the possibility of performing the detection in a wide temperature range from $20^{\circ} \mathrm{C}$ to $300^{\circ} \mathrm{C}[15,118,119]$.

7.3. Self-Cleaning Surfaces. Anodization by high fields can be used to obtain self-cleaning surfaces [120], with adjustable and/or switchable water adhesion [121] and superhydrophobic properties for the corrosion resistance of the base material $[122,123]$, and with antimicrobial properties based on the photocatalysis principle too [124].

Liu et al. [121] reported the use of two polymers responding to different physicochemical stimuli, (i) poly (N-isopropylacrylamide) and (ii) poly (dimethylamino) ethyl methacrylate. These compounds were used to modify the surface of previously anodized alumina substrates. The final composite material changes the adhesion of water droplets as a function of response conditions such as $\mathrm{pH}$, temperature, and electrolyte composition. This type of surfaces will find applications in microfluids, generation of microdroplets, smart coatings, and self-cleaning surfaces.

Similarly, Li and coworkers [120] have commented on the synthesis of alumina surfaces with macro/nanohierarchical structures made on aluminum substrates by an easy and fast anodization method. By means of a modification based on stearic acid, a superhydrophobic surface with a contact angle of $158^{\circ}$ and an ultralow slip angle of about $0^{\circ}$ was achieved. In addition, the superhydrophobic surface showed self-cleaning properties and corrosion resistance.

Also, the antimicrobial properties of the $\mathrm{TiO}_{2}$ nanotubes prepared by the breakdown anodization process were studied. As a main result, the $\mathrm{TiO}_{2}$ nanotubes showed excellent bacterial inhibition percentages of $97.53 \%$ for E. coli and $99.94 \%$ for S. aureus, after $24 \mathrm{~h}$ of UV irradiation. Moreover, the authors demonstrated in the same study that the commercial and control samples did not show any antimicrobial property under the same conditions [124]. Other studies [122, 123] also showed good self-cleaning performance of the anodization process performed on valve metals and, by appropriate chemical modification in a second step, high resistance to corrosion with interesting wettability and anti-icing properties were obtained. In general, these surfaces show promising applications, including outdoor sports equipment, transportation facilities, and industrial machinery.

7.4. Photocatalytic Fuel Cell. The photocatalysis process is the light-induced combustion reaction of organic matter; therefore, if carried out in a separated compartment, it allows oxidation or organic compounds yielding the corresponding electron flux as an added value. To achieve this, the oxygen reduction reaction must be coupled in a cell using an appropriate electrocatalytic material, and determining factors are the control of electric losses during operation of the cell as well as selection of appropriate electrodes $[125,126]$.

Liu et al. $[127,128]$ reported a $\mathrm{TiO}_{2}$-nanotube-array-based photocatalytic fuel cell system using visible light. First, a narrow bandgap semiconductor such as $\mathrm{Cu}_{2} \mathrm{O}$ and $\mathrm{CdS}$ was combined with $\mathrm{TiO}_{2}$ nanotubes. Second, the generation of electrical currents from the photocatalytic oxidation of various refractory organic compounds with 
oxygen reduction at the secondary electrode was evaluated. The studied model compounds included aromatics, azo dyes, pharmaceutical and personal care products, and endocrine-disrupting compounds. The approach demonstrated the possibility of obtaining energy from various refractory organic compounds with simultaneous water cleaning.

Recently, Ye and coworkers [129] evaluated the application of a membrane-free photocatalytic fuel cell composed of a $\mathrm{TiO}_{2}$ nanotube array photoanode and a $\mathrm{Cu}$ cathode for micropollutant removal from water. They reported the most important operation conditions to obtain high performance, including $\mathrm{pH}$, pollutant concentration, the oxygen reactive species that were formed, the presence of chemical substances as inorganic ions in the electrolyte, and the hydrodynamic conditions. Also, significantly enhanced removal of a commonly present aqueous micropollutant, 4-chloro-2 methylphenoxyacetic acid, was obtained.

In general, it was found that the cell performance depended critically on the good conductivity of the high-field anode, as well as on the efficient photocatalytic degradation of the organic compounds. However, the use of appropriate materials, the quantum efficiency, and the design of reactors are aspects that still need to be improved by modern research $[125,126]$.

7.5. $\mathrm{H}_{2}$ Production. Thermodynamically, $\mathrm{H}_{2}$ production during the photocatalytic process is possible when the photoanode has a more negative conduction band potential than the redox potential required to form $\mathrm{H}_{2}$ from water. In general, the reaction rates of photocatalytic processes on numerous semiconducting materials are limited by the kinetics of the charge transfer process to a suitable redox species. Therefore, modifications of the electrodes with cocatalysts, such as $\mathrm{Pt}, \mathrm{Rh}, \mathrm{Ru}, \mathrm{Ag}, \mathrm{Au}$, and its alloys, have been used to promote $\mathrm{H}_{2}$ evolution [22]. Photoanodes based on $\mathrm{TiO}_{2}$ nanotube layers have been reported to be more promising than nanoparticle layers, due to their well-defined geometry on the one hand, but especially because it is more feasible to incorporate cocatalysts, for example, by electrocrystallization and/or simple chemical reduction. Additionally, after the generation of charge carriers by sunlight, the electrons go to the back contact of the photoanode, then, electron lifetime and conductivity become determinant factors for the overall efficiency $[17,22,26,130]$.

Spanu et al. [17] investigated a well-defined charge separation platform for photocatalytic $\mathrm{H}_{2}$ evolution based on a $\mathrm{Pt}-\mathrm{WO}_{3}-\mathrm{TiO}_{2}$ "stacked" structure constructed on anodically grown $\mathrm{TiO}_{2}$ nanotube arrays. These structures show strongly improved photocatalytic $\mathrm{H}_{2}$ evolution, compared to any other single cocatalyst system such as $\mathrm{Pt}-\mathrm{TiO}_{2}, \mathrm{WO}_{3}-\mathrm{TiO}_{2}$, and pristine $\mathrm{TiO}_{2}$ nanotubes. The photocatalytic activity is ascribed to the enhanced charge carrier separation mechanism enabled by the well-defined $\mathrm{TiO}_{2}-\mathrm{WO}_{3}-\mathrm{Pt}$ architecture that provides swift electron transfer through $\mathrm{WO}_{3}$ and towards $\mathrm{Pt}$ for $\mathrm{H}_{2}$ evolution.

Additionally, Spanu et al. [130] remarked that the photocatalytic $\mathrm{H}_{2}$ evolution reaction on pristine $\mathrm{TiO}_{2}$ occurred with low efficiencies due to (i) trapping and recombination of charge carriers and (ii) sluggish electron transfer kinetics.
Recently, this group introduced an approach to fabricate an efficient noble metal-free photocatalytic platform for $\mathrm{H}_{2}$ evolution. By dewetting $\mathrm{NiCu}$ bilayers into alloyed $\mathrm{NiCu}$ cocatalytic nanoparticles at the surface of $\mathrm{TiO}_{2}$ nanotube arrays, they found improvements in $\mathrm{H}_{2}$ production, especially when the metals were in equimolar proportion. The alloyed $\mathrm{NiCu}$ cocatalyst on $\mathrm{TiO}_{2}$ nanotubes allowed them to reach $\mathrm{H}_{2}$ generation rates comparable to those delivered by conventional decoration of $\mathrm{TiO}_{2}$ with noble metals such as platinum.

Finally, we have considered the advantages of using anodic oxide thin films and the possibility of precisely controlling the characteristics of the final semiconductor materials by growing them under high fields. By enhancing charge separation through external application of electric potentials, their performance can be improved to facilitate the technological implementation of industrial photocatalysis. This advantage has been employed in several reactors of different design $[12,16,22,26,80]$, but the industrial production of thin oxide films and photocatalytic reactors based on them is yet to be developed [12,26].

\section{Conclusions}

After reviewing the high-field growth of anodic oxide films for photocatalytic application, three important conclusions can be highlighted: (i) the synthesis of nanostructured metal oxides through high-field anodization allows to control the characteristics of the obtained materials; (ii) the electrochemical assistance of the photocatalytic processes on these materials yields efficient wastewater treatment; and (iii) the measure of reaction rates is important to determine and compare the physicochemical parameters, describing the chemical interactions during photoelectrolysis, and to apply this understanding to the design, operation, and control of reactive systems.

\section{Conflicts of Interest}

The authors declare no conflicts of interest.

\section{Acknowledgments}

We are grateful to the members of the Electrochemistry Group at Simón Bolívar University for many stimulating discussions about the subject of this paper.

\section{References}

[1] V. Etacheri, C. Di Valentin, J. Schneider, D. Bahnemann, and S. C. Pillai, "Visible-light activation of $\mathrm{TiO}_{2}$ photocatalysts: advances in theory and experiments," Journal of Photochemistry and Photobiology C: Photochemistry Reviews, vol. 25, pp. 1-29, 2015.

[2] Y. Lv, W. Yao, R. Zong, and Y. Zhu, "Fabrication of wide range - visible photocatalyst $\mathrm{Bi}_{2} \mathrm{WO}_{6-\mathrm{x}}$ nanoplates via surface oxygen vacancies," Scientific Reports, vol. 6, no. 1, article 19347, pp. 1-6, 2016.

[3] L. Madriz, J. Tatá, and R. Vargas, "The photocatalytic oxidation of 4-chlorophenol using $\mathrm{Bi}_{2} \mathrm{WO}_{6}$ under solar light 
irradiation," International Journal of Photochemistry, vol. 2014, Article ID 387536, 6 pages, 2014.

[4] L. Santos-Juanes, F. S. García Einschlag, A. M. Amat, and A. Arques, "Combining ZVI reduction with photo-Fenton process for the removal of persistent pollutants," Chemical Engineering Journal, vol. 310, no. 2, pp. 484-490, 2017.

[5] R. Vargas and O. Núñez, "Photocatalytic degradation of oil industry hydrocarbons models at laboratory and at pilot-plant scale," Solar Energy, vol. 84, no. 2, pp. 345-351, 2010.

[6] J. Schneider, M. Matsuoka, M. Takeuchi et al., "Understanding $\mathrm{TiO}_{2}$ photocatalysis: mechanisms and materials," Chemical Reviews, vol. 114, no. 19, pp. 9919-9986, 2014.

[7] D. Friedmann, C. Mendive, and D. Bahnemann, " $\mathrm{TiO}_{2}$ for water treatment: parameters affecting the kinetics and mechanisms of photocatalysis," Applied Catalysis B: Environmental, vol. 99, no. 3-4, pp. 398-406, 2010.

[8] M. R. Hoffmann, S. T. Martin, W. Choi, and D. W. Bahnemann, "Environmental applications of semiconductor photocatalysis," Chemical Reviews, vol. 95, no. 1, pp. 69-96, 1995.

[9] D. López, W. Lozada, S. Blanco, L. Madriz, G. Durán, and R. Vargas, "Fotocatálisis de p-nitrofenol sobre películas de $\mathrm{TiO}_{2}$ nanoestructurado," Avances en Ciencia e Ingeniería, vol. 2, no. 4, pp. 47-58, 2011.

[10] L. Madriz, H. Carrero, J. Herrera, A. Cabrera, N. Canudas, and L. Fernández, "Photocatalytic activity of metalloporphyrin-titanium mixtures in microemulsions," Topics in Catalysis, vol. 54, no. 1-4, pp. 236-243, 2011.

[11] L. Madriz, H. Carrero, O. Núñez, R. Vargas, and J. Herrera, "Mechanistic aspects of photocatalytic activity of metalloporphyrin - titanium mixtures in microemulsions," Química Nova, vol. 39, no. 8, pp. 944-950, 2016.

[12] S. Garcia-Segura and E. Brillas, "Applied photoelectrocatalysis on the degradation of organic pollutants in wastewaters," Journal of Photochemistry and Photobiology C: Photochemistry Reviews, vol. 31, pp. 1-35, 2017.

[13] T. Hisatomi, K. Takanabe, and K. Domen, "Photocatalytic water-splitting reaction from catalytic and kinetic perspectives," Catalysis Letters, vol. 145, no. 1, pp. 95-108, 2015.

[14] N. Bao, X. Feng, and C. A. Grimes, "Self-organized one-dimensional $\mathrm{TiO}_{2}$ nanotube/nanowire array films for use in excitonic solar cells: a review," Journal of Nanotechnology, vol. 2012, Article ID 645931, 27 pages, 2012.

[15] G. K. Mor, O. K. Varghese, M. Paulose, K. Shankar, and C. A. Grimes, "A review on highly ordered, vertically oriented $\mathrm{TiO}_{2}$ nanotube arrays: fabrication, material properties, and solar energy applications," Solar Energy Materials \& Solar Cells, vol. 90, no. 14, pp. 2011-2075, 2006.

[16] Y.-C. Nah, I. Paramasivam, and P. Schmuki, "Doped $\mathrm{TiO}_{2}$ and $\mathrm{TiO}_{2}$ nanotubes: synthesis and applications," ChemPhysChem, vol. 11, no. 13, pp. 2698-2713, 2010.

[17] D. Spanu, S. Recchia, S. Mohajernia, P. Schmuki, and M. Altomare, "Site-selective $\mathrm{Pt}$ dewetting on $\mathrm{WO}_{3}$-coated $\mathrm{TiO}_{2}$ nanotube arrays: an electron transfer cascade-based $\mathrm{H}_{2}$ evolution photocatalyst," Applied Catalysis B: Environmental, vol. 237, pp. 198-205, 2018.

[18] V. C. Anitha, R. Zazpe, M. Krbal et al., "Anodic $\mathrm{TiO}_{2}$ nanotubes decorated by Pt nanoparticles using ALD: an efficient electrocatalyst for methanol oxidation," Journal of Catalysis, vol. 365, pp. 86-93, 2018.
[19] M. Zubair, H. Kim, A. Razzaq, C. A. Grimes, and S. I. In, "Solar spectrum photocatalytic conversion of $\mathrm{CO}_{2}$ to $\mathrm{CH}_{4}$ utilizing $\mathrm{TiO}_{2}$ nanotube arrays embedded with graphene quantum dots," Journal of CO2 Utilization, vol. 26, pp. 7079, 2018.

[20] P. Enciso, J.-. D. Decoppet, M. Grätzel, M. Wörner, F. M. Cabrerizo, and M. F. Cerdá, "A cockspur for the DSS cells: Erythrina crista-galli sensitizers," Spectrochimica Acta Part A: Molecular and Biomolecular Spectroscopy, vol. 176, pp. 91-98, 2017.

[21] M. Hojamberdiev, Y. Cai, J. J. M. Vequizo et al., "Binary flux-promoted formation of trigonal $\mathrm{ZnIn}_{2} \mathrm{~S}_{4}$ layered crystals using $\mathrm{ZnS}$-containing industrial waste and their photocatalytic performance for $\mathrm{H}_{2}$ production," Green Chemistry, vol. 20, no. 16, pp. 3845-3856, 2018.

[22] K. Lee, A. Mazare, and P. Schmuki, "One-dimensional titanium dioxide nanomaterials: nanotubes," Chemical Reviews, vol. 114, no. 19, pp. 9385-9454, 2014.

[23] L. M. Peter, "Photoelectrochemistry: from basic principles to photocatalysis," in Photocatalysis: Fundamentals and Perspectives, J. Schneider, D. Bahnemann, J. Ye, G. Li Puma, and D. Dionysiou, Eds., pp. 1-28, RSC Energy and Environmental Series, UK, 2016.

[24] X. Chen and S. S. Mao, "Titanium dioxide nanomaterials: synthesis, properties, modifications, and applications," Chemical Reviews, vol. 107, no. 7, pp. 2891-2959, 2007.

[25] S. Ozkan, A. Mazare, and P. Schmuki, "Critical parameters and factors in the formation of spaced $\mathrm{TiO}_{2}$ nanotubes by self-organizing anodization," Electrochimica Acta, vol. 268, pp. 435-447, 2018.

[26] T. Berger, D. Monllor-Satoca, M. Jankulovska, T. Lana-Villareal, and R. Gómez, "The electrochemistry of nanostructure titania dioxide electrodes," Chem Phys Chem, vol. 13, no. 12, pp. 2824-2875, 2012.

[27] J. M. Macak, H. Hildebrant, U. Marten-Jahns, and P. Schmuki, "Mechanistic aspects and growth of large diameter self-assembly $\mathrm{TiO}_{2}$ nanotubes," Journal of Electroanalytical Chemistry, vol. 621, no. 2, pp. 254-266, 2008.

[28] U. Gaya, Heterogeneous Photocatalysis Using Inorganic Semiconductor Solids, Springer Science + Business Media, Dordrecht, 2014.

[29] C. Schönbein and M. Faraday, "On peculiar voltaic condition of iron,” Philosophical Magazine, vol. 9, pp. 2499-2513, 1836.

[30] M. M. Lohrengel, "Thin anodic oxide layers on aluminium and other valve metals: high field regime," Materials Science and Engineering: R: Reports, vol. 11, no. 6, pp. 243-294, 1993.

[31] J. W. Schultze and M. M. Lohrengel, "Stability, reactivity and breakdown of passive films. Problems of recent and future research," Electrochimica Acta, vol. 45, no. 15-16, pp. 24992513, 2000.

[32] L. Young, Anodic Oxide Films, Academic Press, London, 1961.

[33] M. J. Dignam, "The kinetics of growth of oxides," in Comprehensive Treatise of Electrochemistry, J. O. Bockris, B. E. Conway, E. Yeager, and R. E. White, Eds., vol. 4 of Electrochemical Material Science, Springer, Boston, MA, USA, 1981.

[34] O. Linares-Pérez, V. Fuertes, M. Pérez, and M. López-Teijelo, "Characterization of the anodic growth and dissolution of oxide films on valve metals," Electrochemistry Communications, vol. 10, no. 3, pp. 433-437, 2008. 
[35] P. Acevedo-Peña, G. Vázquez, D. Laverde, J. E. PedrazaRosas, and I. González, "Influence of structural transformations over the electrochemical behavior of $\mathrm{Ti}$ anodic films grown in $0.1 \mathrm{M} \mathrm{NaOH}$," Journal of Solid State Electrochemistry, vol. 14, no. 5, pp. 757-767, 2010.

[36] P. Acevedo-Peña, J. Vazquez-Arenas, R. Cabrera-Sierra, L. Lartundo-Rojas, and I. Gonzalez, "Ti anodization in alkaline electrolyte: the relationship between transport of defects, film hydration and composition," Journal of the Electrochemical Society, vol. 160, no. 6, pp. C277-C284, 2013.

[37] C. E. B. Marino, E. M. de Oliveira, R. C. Rocha-Filho, and S. R. Biaggio, "On the stability of thin-anodic-oxide films of titanium in acid phosphoric media," Corrosion Science, vol. 43, no. 8, pp. 1465-1476, 2001.

[38] J. L. Trompette, L. Massot, L. Arurault, and S. Fontorbes, "Influence of the anion specificity on the anodic polarization of titanium," Corrosion Science, vol. 53, no. 4, pp. 1262-1268, 2011.

[39] E. M. Patrito, R. M. Torresi, E. P. M. Leiva, and V. A. Macagno, "Potentiodynamic and AC impedance investigation of anodic zirconium oxide films," Journal of the Electrochemical Society, vol. 137, no. 2, pp. 524-530, 1990.

[40] M. E. Sibert, "Electrochemical oxidation of titanium surfaces," Journal of the Electrochemical Society, vol. 110, no. 1, pp. 65-72, 1963.

[41] V. Brunetti, H. M. Villullas, and M. López Teijelo, “Anodic film formation on silver in solutions containing chromate," Electrochimica Acta, vol. 44, no. 17, pp. 2843-2851, 1999.

[42] V. Brunetti and M. López Teijelo, "Oxide/hydroxide films on tin. Part I: kinetic aspects of the electroformation and electroreduction of the films," Journal of Electroanalytical Chemistry, vol. 613, no. 1, pp. 9-15, 2008.

[43] V. Brunetti and M. López Teijelo, "Oxide/hydroxide films on tin. II: characterization of the anodic growth in alkaline solutions," Journal of Electroanalytical Chemistry, vol. 613, no. 1, pp. 16-22, 2008.

[44] F. A. Filippin, O. E. Linarez Pérez, M. López Teijelo, R. D. Bonetto, J. Trincavelli, and L. B. Avalle, "Thickness determination of electrochemical titanium oxide $\left(\mathrm{Ti} / \mathrm{TiO}_{2}\right)$ formed in $\mathrm{HClO}_{4}$ solutions," Electrochimica Acta, vol. 129, pp. 266275, 2014.

[45] M. A. Pérez and M. López Teijelo, "Ellipsometric study of $\mathrm{WO}_{3}$ films dissolution in aqueous solutions," Thin Solid Films, vol. 449, no. 1-2, pp. 138-146, 2004.

[46] M. A. Pérez and M. López Teijelo, "Cathodic behavior of bismuth. I. Ellipsometric study of the electroreduction of thin $\mathrm{Bi}_{2} \mathrm{O}_{3}$ films," Journal of Electroanalytical Chemistry, vol. 583, no. 2, pp. 212-220, 2005.

[47] M. A. Pérez, O. E. Linarez Pérez, and M. López Teijelo, "Cathodic behavior of bismuth. II. Electrochemical and ellipsometric study of the hydrogen insertion into bulk bismuth," Journal of Electroanalytical Chemistry, vol. 596, no. 2, pp. 149-156, 2006.

[48] A. Aladjem, "Anodic oxidation of titanium and its alloys," Journal of Materials Science, vol. 8, no. 5, pp. 688-704, 1973.

[49] V. Zwilling, E. Darque-Ceretti, A. Boutry-Forveille, D. Perrin, and M. Aucouturier, "Structure and physicochemistry of anodic oxide films on titanium and TA6V alloy," Surface and Interface Analysis, vol. 27, no. 7, pp. 629-637, 1999.

[50] J. M. Macak, H. Tsuchiya, A. Ghicov et al., “ $\mathrm{TiO}_{2}$ nanotubes: self-organized electrochemical formation, properties and applications," Current Opinion in Solid State and Materials Science, vol. 11, no. 1-2, pp. 3-18, 2007.

[51] G. Nicolis and I. Prigogine, Self-Organization in Nonequilibrium Systems: from Dissipative Structures to Order through Fluctuations, Wiley, New York, NY, USA, 1977.

[52] A. Maimone, S. Camero, and S. Blanco, "Caracterización del óxido de titanio obtenido mediante tratamiento térmico y anodizado electroquímico," Revista de la Facultad de Ingeniería Universidad Central de Venezuela, vol. 30, no. 1, pp. 189-200, 2015.

[53] F. Fabregat-Santiago, G. Garcia-Belmonte, I. Mora-Seró, and J. Bisquert, "Characterization of nanostructured hybrid and organic solar cells by impedance spectroscopy," Physical Chemistry Chemical Physics, vol. 13, no. 20, pp. 9083-9118, 2011.

[54] M. E. Orazem and B. Tribollet, Electrochemical Impedance Spectroscopy, Wiley, New York, NY, USA, 2008.

[55] D. A. Buttry and M. D. Ward, "Measurement of interfacial processes at electrode surfaces with the electrochemical quartz crystal microbalance," Chemical Reviews, vol. 92, no. 6, pp. 1355-1379, 1992.

[56] N. Wayne, Accelerating Testing: Statistical Models, Test Plants and Data Analysis, Wiley-Interscience, New Jersey, USA, 1990.

[57] A. Cantarero, "Raman scattering applied to materials science," Procedia Materials Science, vol. 9, pp. 113-122, 2015.

[58] F. Zaera, "Probing liquid/solid interfaces at the molecular level," Chemical Reviews, vol. 112, no. 5, pp. 2920-2986, 2012.

[59] O. S. Heavens, Optical Properties of Thin Solid Films, Dover Publications, INC., New York, NY, USA, 1991.

[60] J. I. Pankove, Optical Processes in Semiconductors, Dover Publications, INC., New York, NY, USA, 1975.

[61] A. Knoks, J. Kleperis, and L. Grinberga, "Raman spectral identification of phase distribution in anodic titanium dioxide coating," Functional Materials, vol. 66, no. 4, pp. 422-429, 2017.

[62] H. Vašková, "A powerful tool for material identification: Raman spectroscopy," International Journal of Mathematical Models and Methods in Applied Sciences, vol. 7, no. 5, pp. 1205-1212, 2011.

[63] L. M. Peter, "Dynamic aspects of semiconductor photoelectrochemistry," Chemical Reviews, vol. 90, no. 5, pp. 753769, 1990.

[64] N. Sato, Electrochemistry at Metal and Semiconductor Electrodes, Elsevier, Amsterdam, 1998.

[65] A. Hakki, J. Schneider, and D. Bahnemann, "Understanding the chemistry of photocatalytic processes," in Photocatalysis: Fundamentals and Perspectives, J. Schneider, D. Bahnemann, J. Ye, G. Li Puma, and D. Dionysiou, Eds., pp. 29-50, RSC Energy and Environmental Series, UK, 2016.

[66] U. Gaya and A. Abdullah, "Heterogeneous photocatalytic degradation of organic contaminants over titanium dioxide: a review of fundamentals, progress and problems," Journal of Photochemistry and Photobiology C: Photochemistry Reviews, vol. 9, no. 1, pp. 1-12, 2008.

[67] S. Malato, P. Fernández-Ibáñez, M. Maldonado, J. Blanco, and W. Gernjak, "Decontamination and disinfection of water by solar photocatalysis: recent overview and trends," Catalysis Today, vol. 147, no. 1, pp. 1-59, 2009.

[68] F. Machuca-Martínez, M. A. Mueses, J. Colina-Márquez, and G. Li Puma, "Photocatalytic reactor modeling," in 
Photocatalysis: Fundamentals and Perspectives, J. Schneider, D. Bahnemann, J. Ye, G. Li Puma, and D. Dionysiou, Eds., pp. 29-50, RSC Energy and Environmental Series, UK, 2016.

[69] D. I. Naranjo, S. J. García-Vergara, and S. Blanco, "Scanning electron microscopy of heat treated $\mathrm{TiO}_{2}$ nanotubes arrays obtained by anodic oxidation," Journal of Physics: Conference Series, vol. 935, article 012025, 2017.

[70] R. Vargas and O. Núñez, "Hydrogen bond interactions at the $\mathrm{TiO}_{2}$ surface: their contribution to the $\mathrm{pH}$ dependent photo-catalytic degradation of p-nitrophenol," Journal of Molecular Catalysis A: Chemical, vol. 300, no. 1-2, pp. 6571, 2009.

[71] W. Wang, "Effect of solution $\mathrm{pH}$ on the adsorption and photocatalytic reaction behaviors of dyes using $\mathrm{TiO}_{2}$ and Nafion-coated $\mathrm{TiO}_{2}$," Colloids and Surfaces A: Physicochemical and Engineering Aspects, vol. 302, no. 1-3, pp. 261-268, 2007.

[72] M. Mrowetz and E. Selli, "Photocatalytic degradation of formic and benzoic acids and hydrogen peroxide evolution in $\mathrm{TiO}_{2}$ and $\mathrm{ZnO}$ water suspensions," Journal of Photochemistry and Photobiology A: Chemistry, vol. 180, no. 1-2, pp. 15-22, 2006.

[73] H. Mansilla, C. Bravo, R. Ferreyra et al., "Photocatalytic EDTA degradation on suspended and immobilized $\mathrm{TiO}_{2}$," Journal of Photochemistry and Photobiology A: Chemistry, vol. 181, no. 2-3, pp. 188-194, 2006.

[74] M. Tariq, M. Faisal, M. Muneer, and D. Bahnemann, "Photochemical reactions of a few selected pesticide derivatives and other priority organic pollutants in aqueous suspensions of titanium dioxide," Journal of Molecular Catalysis A: Chemical, vol. 265, no. 1-2, pp. 231-236, 2007.

[75] D. Carvajal, R. Vargas, C. Borrás, S. Blanco, J. Mostany, and B. R. Scharifker, "Photo (electro) oxidation of organic compounds with strong adsorption properties on $\mathrm{TiO}_{2}$ : kinetic model," Catalisis, vol. 5, pp. 89-96, 2016.

[76] G. Pardo, R. Vargas, and O. Núñez, "Photocatalytic $\mathrm{TiO}_{2}$-assisted decomposition of Triton X-100: inhibition of $p$-nitrophenol degradation," Journal of Physical Organic Chemistry, vol. 21, no. 12, pp. 1072-1078, 2008.

[77] L. Madriz, M. Parra, R. Vargas, B. R. Scharifker, O. Núñez, and D. Carvajal, "Fotocatálisis heterogénea bajo luz solar basada en $\mathrm{TiO}_{2} \mathrm{y} \mathrm{Bi}_{2} \mathrm{WO}_{6}$ : aplicaciones ambientales," Revista de la Universidad del Zulia, vol. 7, no. 18, pp. 11-54, 2016.

[78] M. Zlamal, J. M. Macak, P. Schmuki, and J. Krýsa, "Electrochemically assisted photocatalysis on self-organized $\mathrm{TiO}_{2}$ nanotubes," Electrochemistry Communications, vol. 9, no. 12 , pp. $2822-2826,2007$.

[79] A. G. Kontos, A. I. Kontos, D. S. Tsoukleris et al., "Photo-induced effects on self-organized $\mathrm{TiO}_{2}$ nanotube arrays: the influence of surface morphology," Nanotechnology, vol. 20, no. 4, article 045603, 2009.

[80] M. A. Lazar, S. Varghese, and S. S. Nair, "Photocatalytic water treatment by titanium dioxide: recent updates," Catalysts, vol. 2, no. 4, pp. 572-601, 2012.

[81] H. Tang, Y. Xu, and Q. Zhang, "Preparation of Ag nanoparticle surface modified $\mathrm{TiO}_{2}$ nanotube arrays and establishment of a catalytic kinetic model," Advances in Energy Science and Environment Engineering, vol. 1829, pp. 0200401-0200405, 2017.

[82] P. A. Mandelbaum, A. E. Regazzoni, M. A. Blesa, and S. A. Bilmes, "Photo-electro-oxidation of alcohols on titanium dioxide thin film electrodes," The Journal of Physical Chemistry B, vol. 103, no. 26, pp. 5505-5511, 1999.

[83] M. E. Calvo, R. J. Candal, and S. A. Bilmes, "Photooxidation of organic mixtures on biased $\mathrm{TiO}_{2}$ films," Environmental Science and Technology, vol. 35, no. 20, pp. 4132-4138, 2001.

[84] N. Wang, Y. Ma, J. Chen et al., "Defect-induced betavoltaic enhancement in black titania nanotube arrays," Nanoscale, vol. 10, no. 27, pp. 13028-13036, 2018.

[85] L. Yu, C. H. MingLi, Y. Zhang, J. He, X. Zhou, and H. Zhu, "Photoelectrochemical properties of $\mathrm{N}$ doped black $\mathrm{TiO} 2$ nanotube arrays," Materials Letters, vol. 216, pp. 239-242, 2018.

[86] M. Plodinec, I. Grcic, M. G. Willinger et al., "Black $\mathrm{TiO}_{2}$ nanotube arrays decorated with $\mathrm{Ag}$ nanoparticles for enhanced visible-light photocatalytic oxidation of salicylic acid," Journal of Alloys and Compounds, vol. 776, pp. 883896, 2019.

[87] K. Du, G. Liu, X. Chen, and K. Wang, "Fast charge separation and photocurrent enhancement on black $\mathrm{TiO}_{2}$ nanotubes co-sensitized with Au nanoparticles and PbS quantum dots," Electrochimica Acta, vol. 277, pp. 244-254, 2018.

[88] Y. Yang, L. C. Kao, Y. Liu et al., "Cobalt-doped black $\mathrm{TiO}_{2}$ nanotube array as a stable anode for oxygen evolution and electrochemical wastewater treatment," ACS Catalysis, vol. 8, no. 5, pp. 4278-4287, 2018.

[89] H. Cui, W. Zhao, C. Yang et al., "Black $\mathrm{TiO}_{2}$ nanotube arrays for high-efficiency photoelectrochemical water-splitting," Journal of Materials Chemistry A, vol. 2, no. 23, pp. 86128616, 2014.

[90] E. Liu, P. Xue, J. Jia et al., “CdSe modified $\mathrm{TiO}_{2}$ nanotube arrays with $\mathrm{Ag}$ nanoparticles as electron transfer channel and plasmonic photosensitizer for enhanced photoelectrochemical water splitting," Journal of Physics D: Applied Physics, vol. 51, no. 30, article 305106, 2018.

[91] P. Roy, S. Berger, and P. Schmuki, " $\mathrm{TiO}_{2}$ nanotubes: synthesis and applications," Angewandte Chemie International Edition, vol. 50, no. 13, pp. 2904-2939, 2011.

[92] S. Berger, H. Tsuchiya, A. Ghicov, and P. Schmuki, "High photocurrent conversion efficiency in self-organized porous $\mathrm{WO}_{3}$," Applied Physics Letters, vol. 88, no. 20, article 203119, 2006.

[93] A. Ghicov, S. Aldabergenova, H. Tsuchyia, and P. Schmuki, " $\mathrm{TiO}_{2}-\mathrm{Nb}_{2} \mathrm{O}_{5}$ nanotubes with electrochemically tunable morphologies," Angewandte Chemie International Edition, vol. 45, no. 42, pp. 6993-6996, 2006.

[94] I. Paramasivam, Y.-C. Nah, C. Das, N. K. Shrestha, and P. Schmuki, " $\mathrm{WO}_{3} / \mathrm{TiO}_{2}$ nanotubes with strongly enhanced photocatalytic activity," Chemistry - A European Journal, vol. 16, no. 30, pp. 8993-8997, 2010.

[95] P. Agarwal, I. Paramasivam, N. K. Shrestha, and P. Schmuki, " $\mathrm{MoO}_{3}$ in self-organized $\mathrm{TiO}_{2}$ nanotubes for enhanced photocatalytic activity," Chemistry-An Asian Journal, vol. 5, no. 1, pp. 66-69, 2010.

[96] I. Paramasivam, J. M. Macak, A. Ghicov, and P. Schmuki, "Enhanced photochromism of Ag loaded self-organized $\mathrm{TiO}_{2}$ nanotube layer," Chemical Physics Letters, vol. 445, no. 4-6, pp. 233-237, 2007.

[97] Y.-. Y. Song, P. Roy, I. Paramasivam, and P. Schmuki, "Voltage-induced payload release and wettability control on $\mathrm{TiO}_{2}$ and $\mathrm{TiO}_{2}$ nanotubes," Angewandte Chemie International Edition, vol. 49, no. 2, pp. 351-354, 2010. 
[98] I. Mora-Seró, T. Lana-Villarreal, J. Bisquert, Á. Pitarch, R. Gómez, and P. Salvador, "Photoelectrochemical behavior of nanostructured $\mathrm{TiO}_{2}$ thin-film electrodes in contact with aqueous electrolytes containing dissolved pollutants: a model for distinguishing between direct and indirect interfacial hole transfer from photocurrent measurements," The Journal of Physical Chemistry B, vol. 109, no. 8, pp. 3371-3380, 2005.

[99] D. Jiang, S. Zhang, and H. Zhao, "Photocatalytic degradation characteristics of different organic compounds at $\mathrm{TiO}_{2}$ nanoporous film electrodes with mixed anatase/rutile phases," Environmental Science \& Technology, vol. 41, no. 1, pp. 303-308, 2007.

[100] H. Zhao, D. Jiang, S. Zhang, and W. Wen, "Photoelectrocatalytic oxidation of organic compounds at nanoporous $\mathrm{TiO}_{2}$ electrodes in a thin-layer photoelectrochemical cell," Journal of Catalysis, vol. 250, no. 1, pp. 102-109, 2007.

[101] D. Jiang, H. Zhao, S. Zhang, and R. John, "Kinetic study of photocatalytic oxidation of adsorbed carboxylic acids at $\mathrm{TiO}_{2}$ porous films by photoelectrolysis," Journal of Catalysis, vol. 223, no. 1, pp. 212-220, 2004.

[102] D. Monllor-Satoca and R. Gómez, "A photoelectrochemical and spectroscopic study of phenol and catechol oxidation on titanium dioxide nanoporous electrodes," Electrochimica Acta, vol. 55, no. 15, pp. 4661-4668, 2010.

[103] Y. Xie, "Photoelectrochemical application of nanotubular titania photoanode," Electrochimica Acta, vol. 51, no. 17, pp. 3399-3406, 2006.

[104] H. Liu, S. Cheng, M. Wu et al., "Photoelectrocatalytic degradation of sulfosalicylic acid and its electrochemical impedance spectroscopy investigation," The Journal of Physical Chemistry A, vol. 104, no. 30, pp. 7016-7020, 2000.

[105] T. A. Egerton, "Does photoelectrocatalysis by $\mathrm{TiO}_{2}$ work?," Journal of Chemical Technology \& Biotechnology, vol. 86, no. 8, pp. 1024-1031, 2011.

[106] M. Tian, G. Wu, B. Adams, J. Wen, and A. Chen, "Kinetics of photoelectrocatalytic degradation of nitrophenols on nanostructured $\mathrm{TiO}_{2}$ electrodes," The Journal of Physical Chemistry C, vol. 112, no. 3, pp. 825-831, 2008.

[107] B. Su, Y. Ma, Y. Du, and C. Wang, "Study of photoelectrocatalytic degradation behavior of p-nitrophenol with nano- $\mathrm{TiO}_{2}$ modified film at a rotating ring-disk electrode," Electrochemistry Communications, vol. 11, no. 6, pp. 11541157, 2009.

[108] H. Hidaka, T. Shimura, K. Ajisaka, S. Horikoshi, J. Zhao, and N. Serpone, "Photoelectrochemical decomposition of amino acids on a $\mathrm{TiO}_{2}$ /OTE particulate film electrode," Journal of Photochemistry and Photobiology A: Chemistry, vol. 109, no. 2, pp. 165-170, 1997.

[109] J. Carvalho Cardoso, T. Mescoloto Lizier, and M. V. Boldrin Zanoni, "Highly ordered $\mathrm{TiO}_{2}$ nanotube arrays and photoelectrocatalytic oxidation of aromatic amine," Applied Catalysis B: Environmental, vol. 99, no. 1-2, pp. 96-102, 2010.

[110] H. Hidaka, K. Ajisaka, S. Horikoshi et al., "Comparative assessment of the efficiency of $\mathrm{TiO}_{2} / \mathrm{OTE}$ thin film electrodes fabricated by three deposition methods: photoelectrochemical degradation of the DBS anionic surfactant," Journal of Photochemistry and Photobiology A: Chemistry, vol. 138, no. 2, pp. 185-192, 2001.

[111] Y. Xin, H. Liu, L. Han, and Y. Zhou, "Comparative study of photocatalytic and photoelectrocatalytic properties of alachlor using different morphology $\mathrm{TiO}_{2} / \mathrm{Ti}$ photoelectrodes,"
Journal of Hazardous Materials, vol. 192, no. 3, pp. 18121818, 2011.

[112] K. Vinodgopal and P. V. Kamat, "Enhanced rates of photocatalytic degradation of an azo dye using $\mathrm{SnO}_{2} / \mathrm{TiO}_{2}$ coupled semiconductor thin films," Environmental Science \& Technology, vol. 29, no. 3, pp. 841-845, 1995.

[113] A. Turolla, M. Fumagalli, M. Bestetti, and M. Antonelli, "Electrophotocatalytic decolorization of an azo dye on $\mathrm{TiO}_{2}$ self-organized nanotubes in a laboratory scale reactor," Desalination, vol. 285, pp. 377-382, 2012.

[114] K. Vinodgopal, I. Bedja, and P. V. Kamat, "Nanostructured semiconductor films for photocatalysis. Photoelectrochemical behavior of $\mathrm{SnO}_{2} / \mathrm{TiO}_{2}$ composite systems and its role in photocatalytic degradation of a textile azo dye," Chemistry of Materials, vol. 8, no. 8, pp. 2180-2187, 1996.

[115] J. Zhang, B. Zhou, Q. Zheng et al., "Photoelectrocatalytic COD determination method using highly ordered $\mathrm{TiO}_{2}$ nanotube array," Water Research, vol. 43, no. 7, pp. 19861992, 2009.

[116] J. Qiu, S. Zhang, and H. Zhao, "Nanostructured $\mathrm{TiO}_{2}$ photocatalysts for the determination of organic pollutants," Journal of Hazardous Materials, vol. 211-212, pp. 381-388, 2012.

[117] J. Zhang, X. Chan, and A. Chen, "Determination of chemical oxygen demand based on photoelectrocatalysis of nanoporous $\mathrm{TiO}_{2}$ electrodes," Sensors and Actuators B: Chemical, vol. 223, pp. 664-670, 2016.

[118] Z. Li, D. Ding, Q. Liu, C. Ning, and X. Wang, "Ni-doped $\mathrm{TiO}_{2}$ nanotubes for wide-range hydrogen sensing," Nanoscale Research Letters, vol. 9, no. 1, pp. 118-126, 2014.

[119] Z. Chen, M. Cong, J. Hu, Z. Yang, and Z. Chen, "Preparation of functionalized $\mathrm{TiO}_{2}$ nanotube arrays and their applications," Science of Advanced Materials, vol. 8, no. 6, pp. 1231-1241, 2016.

[120] S. Y. Li, J. Wang, Y. Li, and C. W. Wang, "Superhydrophobic surface based on self-aggregated alumina nanowire clusters fabricated by anodization," Microelectronic Engineering, vol. 142, pp. 70-76, 2015.

[121] X. Liu, Q. Ye, B. Yu, Y. Liang, W. Liu, and F. Zhou, "Switching water droplet adhesion using responsive polymer brushes," Langmuir, vol. 26, no. 14, pp. 12377-12382, 2010.

[122] S. Zheng, C. Li, Q. Fu et al., "Fabrication of self-cleaning superhydrophobic surface on aluminum alloys with excellent corrosion resistance," Surface and Coatings Technology, vol. 276, pp. 341-348, 2015.

[123] S. Zheng, C. Li, Q. Fu et al., "Development of stable superhydrophobic coatings on aluminum surface for corrosion-resistant, self-cleaning, and anti-icing applications," Materials \& Design, vol. 93, pp. 261-270, 2016.

[124] J. Podporska-Carroll, E. Panaitescu, B. Quilty, L. Wang, L. Menon, and S. C. Pillai, "Antimicrobial properties of highly efficient photocatalytic TiO2 nanotubes," Applied Catalysis B: Environmental, vol. 176-177, pp. 70-75, 2015.

[125] P. Lianos, "Production of electricity and hydrogen by photocatalytic degradation of organic wastes in a photoelectrochemical cell: the concept of the photofuelcell: a review of a re-emerging research field," Journal of Hazardous Materials, vol. 185, no. 2-3, pp. 575-590, 2011.

[126] A. Sfaelou and P. Lianos, "Photoactivated fuel cells (PhotoFuelCells). An alternative source of renewable energy with environmental benefits," AIMS Materials Science, vol. 3, no. 1, pp. 270-288, 2016. 
[127] Y. Liu, J. Li, B. Zhou, H. Chen, Z. Wang, and W. Cai, "A $\mathrm{TiO}_{2}$-nanotube-array-based photocatalytic fuel cell using refractory organic compounds as substrates for electricity generation," Chemical Communications, vol. 47, no. 37, pp. 10314-10316, 2011.

[128] Y. Liu, J. Li, B. Zhou et al., "Efficient electricity production and simultaneously wastewater treatment via a high-performance photocatalytic fuel cell," Water Research, vol. 45, no. 13, pp. 3991-3998, 2011.

[129] Y. Ye, H. Bruning, X. Li, D. Yntema, and H. H. M. Rijnaarts, "Significant enhancement of micropollutant photocatalytic degradation using a $\mathrm{TiO}_{2}$ nanotube array photoanode based photocatalytic fuel cell," Chemical Engineering Journal, vol. 354, pp. 553-562, 2018.

[130] D. Spanu, S. Recchia, S. Mohajernia et al., "Templated dewetting-alloying of $\mathrm{NiCu}$ bilayers on $\mathrm{TiO}_{2}$ nanotubes enables efficient noble-metal-free photocatalytic $\mathrm{H}_{2}$ evolution," ACS Catalysis, vol. 8, no. 6, pp. 5298-5305, 2018. 

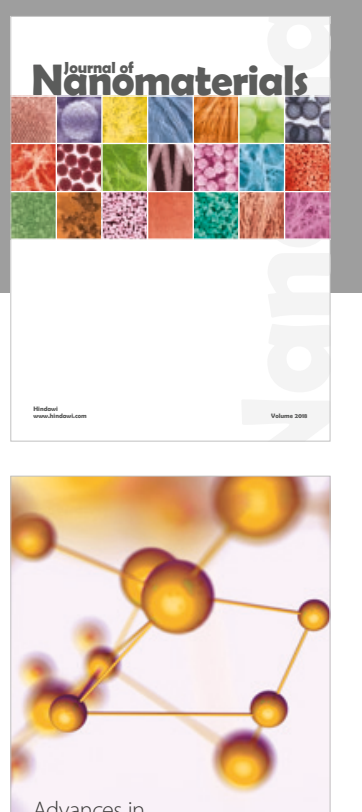

Physical Chemistry
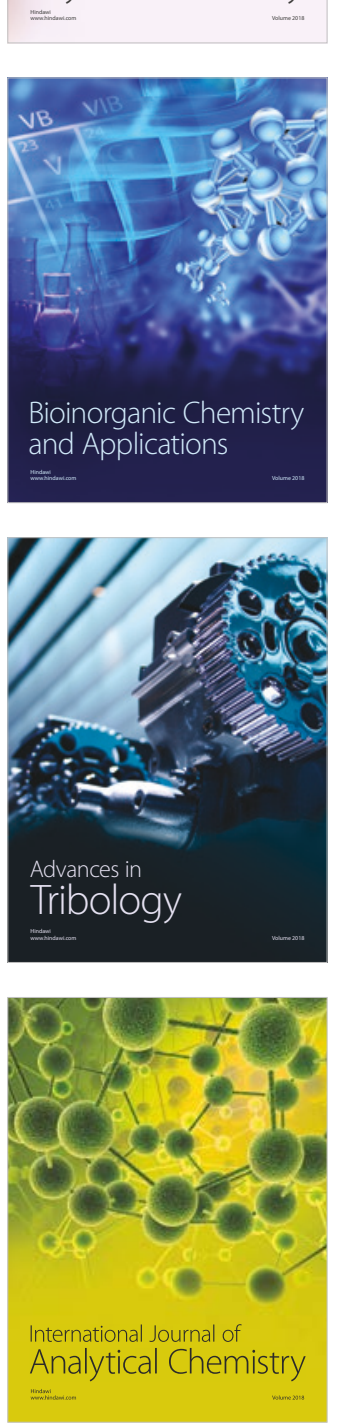

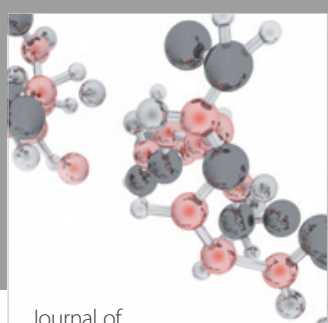

Analytical Methods

in Chemistry

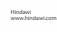

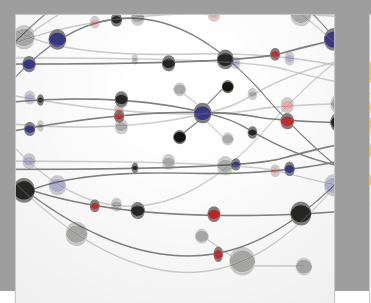

The Scientific World Journal

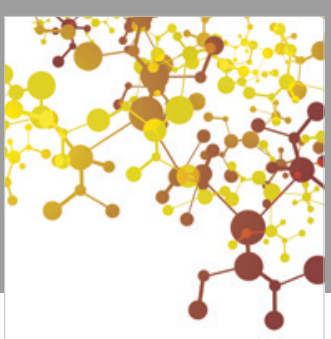

Journal of

Applied Chemistry
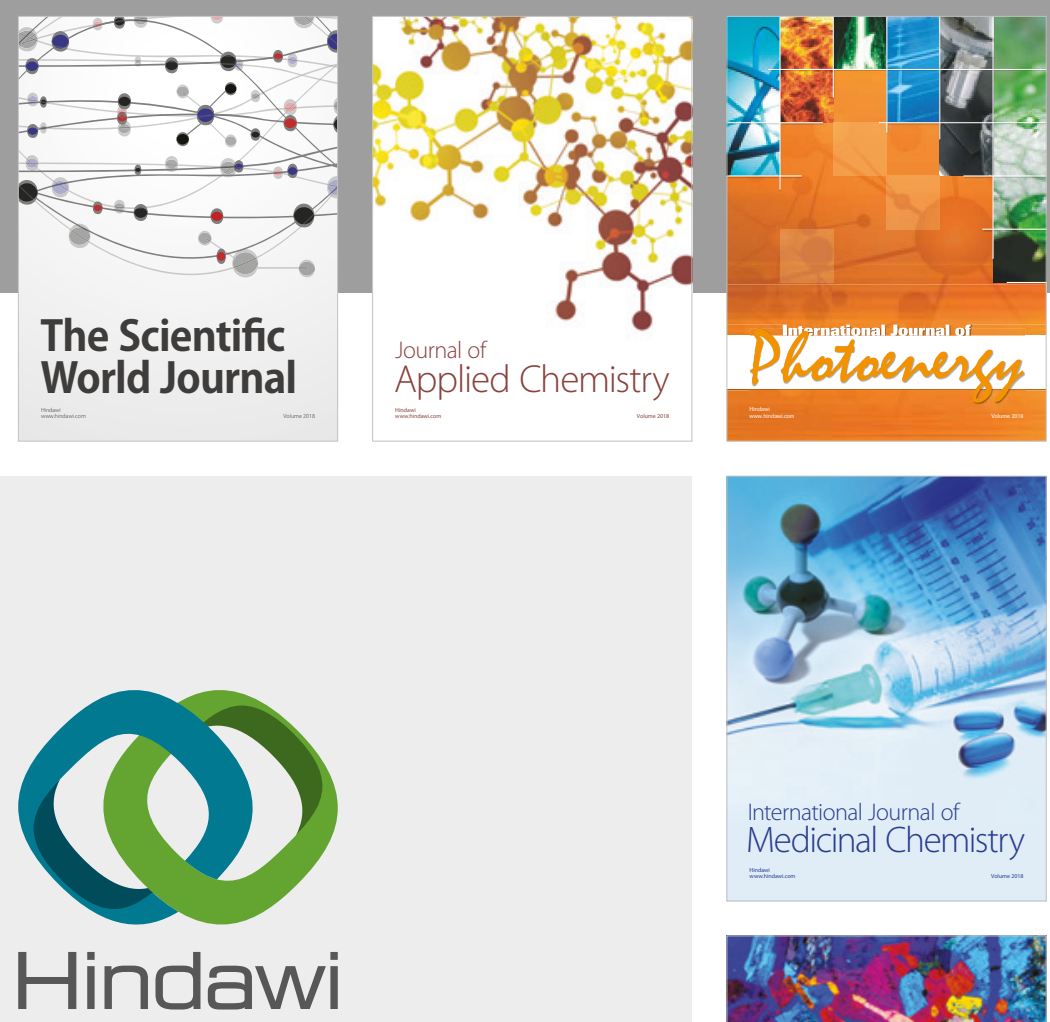

Submit your manuscripts at

www.hindawi.com
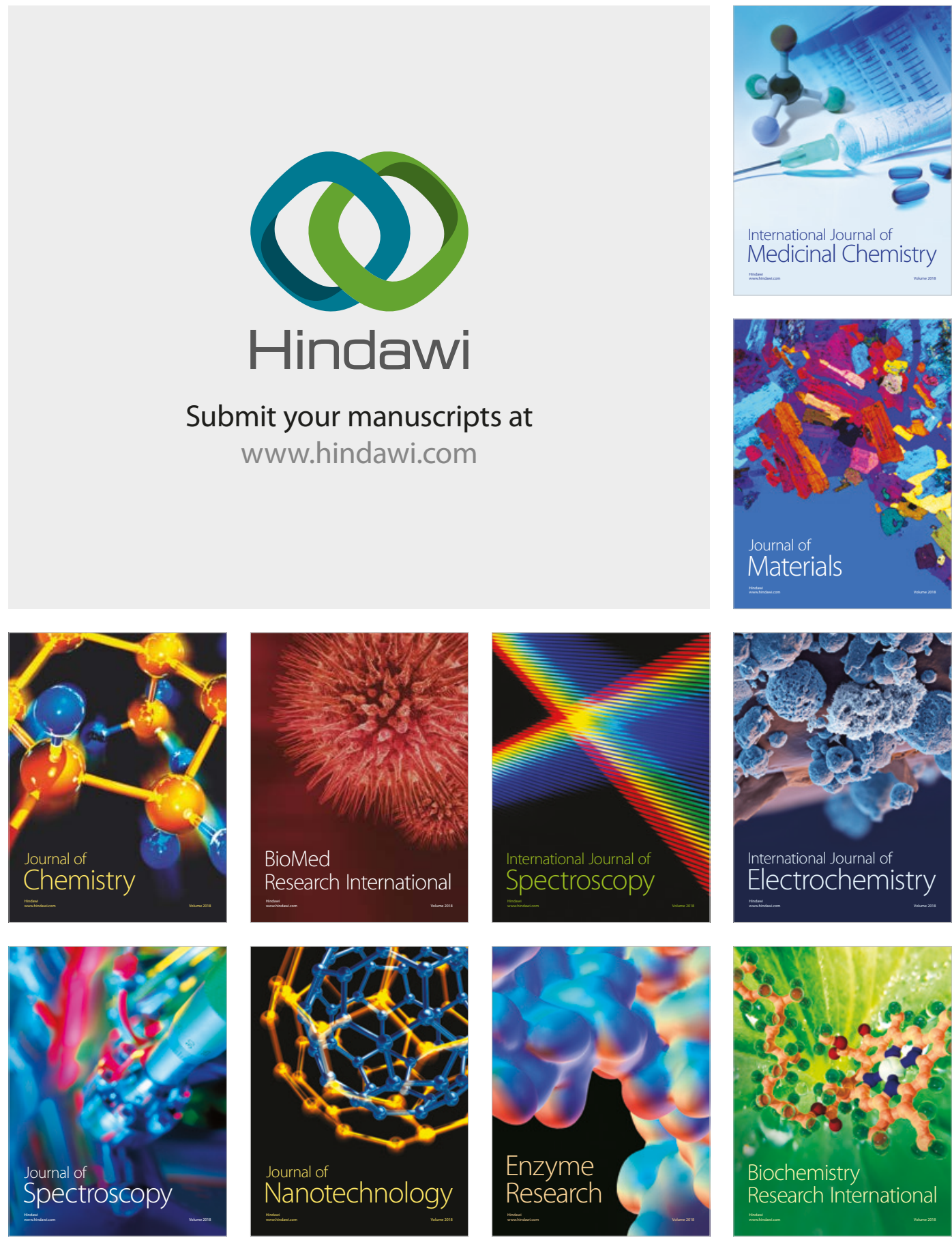
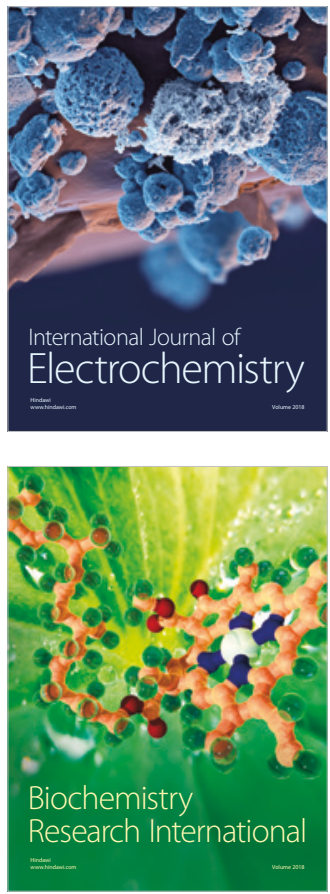